Discussion Paper No. 992

\title{
EFFICIENCY AND VOLUNTARY REDISTRIBUTION UNDER INEQUALITY
}

\author{
Masaki Aoyagi \\ Naoko Nishimura \\ Yoshitaka Okano
}

March 2017

The Institute of Social and Economic Research Osaka University

6-1 Mihogaoka, Ibaraki, Osaka 567-0047, Japan 


\title{
Efficiency and Voluntary Redistribution under Inequality *
}

\author{
Masaki Aoyagi Naoko Nishimura \\ Osaka University Shinshu University \\ Yoshitaka Okano \\ Kochi University of Technology
}

March 13, 2017

\begin{abstract}
This paper presents an experimental analysis of $2 \times 2$ coordination games in which player 1 earns a substantially higher payoff than player 2 except in the inefficient equilibrium where they earn the same payoffs. The main focus is on the comparison of two treatments with and without the ex post redistribution stage in which both players may voluntarily transfer their payoffs earned in the game to the other player. We find that (1) the transfer opportunity raises the probability of coordination on an efficient equilibrium, (2) a transfer from player 1 to player 2 is positive, and is higher when player 2 chooses the action corresponding to the efficient equilibrium, and hence (3) the transfer opportunity tends to improve the efficiency and equity of the final outcome. Furthermore, these tendencies are stronger when the two players have conflicting interests over the two equilibria than when they have common interests.

Key words: heterogeneity, equity, efficiency, transfer, reciprocity, laboratory experiments

Journal of Economic Literature Classification Numbers: C72, D03, D31, D63
\end{abstract}

\section{Introduction}

Inequality is a basic trait of the modern society. The income share of the top $0.1 \%$ in the U.S. exceeds 7\%, and the Gini coefficient for the U.S. households rose to .479 in 2015 from .386 in $1968 .^{1}$ The same increasing trend in inequality is found in many of the industrialized countries. The coexistence of the haves and the have-nots in

\footnotetext{
*Financial support from the JSPS (grant numbers: 21653016, 24653048, 15K13006, 22330061, 15H03328, 23560216, and 16H03597) and the Joint Usage/Research Center at ISER, Osaka University is gratefully acknowledged.

${ }^{1}$ US Census Bureau. http://www.census.gov/data/tables/time-series/demo/incomepoverty/historical-income-households.html
} 
the society will inevitably create an encounter between them. For example, a CEO with astronomical salaries manages his company's blue-color workers who earn a little more than the minimum wage, or poor students earn their way to college to compete against classmates from affluent families. While economics in general recognizes the importance of inequality, there is relatively little experimental work on how distributive inequality may affect the strategic interaction between individuals with highly asymmetric backgrounds. We are interested in such questions as: Is the behavior of the less privilege people driven by their anticipation of positive reciprocity from their privileged counterparts? How does inequality aversion interplay with the strategic interactions between the privileged and non-privileged individuals? Does the opportunity to make voluntary transfers help mitigate inequality and raise efficiency through better coordination?

In this paper, we use a laboratory experiment to study how the presence of inequality between two subjects affects their play in a simple simultaneous-move game with and without the possibility of income redistribution ex post. Specifically, we let subjects play an inequality game. which is a $2 \times 2$ coordination game with two Nash equilibria. Inequality derives from the fact that player 1 earns a strictly higher payoff than player 2 at every action profile other than the inefficient equilibrium, where they earn the same payoff. The sum of payoffs is substantially higher at the efficient NE. It follows that the players face a fundamental trade-off between efficiency and equity in this game: the players achieve equity but not efficiency in one NE, whereas they achieve efficiency but not equity in the other NE. The inequality games are further classified into common-interest (CM) inequality games in which both players prefer the efficient NE to the inefficient NE, and conflictinginterest $(\mathrm{CF})$ inequality games in which player 1 prefers the efficient NE but player 2 prefers the inefficient NE. The inequality games are also parametrized by the level of inequality between the two players as measured by the payoff ratio at the efficient NE.

Our main objective is to analyze the play of the inequality game with and without the ex post redistribution stage in which each player may voluntarily transfer their payoff to the other player. Of course, in any subgame perfect equilibrium of the two-stage game between the self-interested players, no ex post redistribution takes place and hence the presence of this additional stage makes no difference to the final allocation.

In our experiment, each subject is randomly assigned the role of either player 1 or player 2, and is randomly and anonymously matched with a subject who is assigned the other role. The subject role stays the same throughout the experiment. Our first treatment is the dictator decision treatment in which one of the paired subjects chooses one of the four alternatives that correspond to the action profiles of the inequality game. We find that the subjects' preferences are best characterized by own payoff maximization rather than inequality or inefficiency aversion. The next two treatments involve strategic interaction between the subjects: The subjects play 
a series of inequality games in each treatment with the ex post redistribution stage added only in the third treatment. We find that the presence of the redistribution stage significantly increases the rate with which the two subjects coordinate on the efficient NE. This effect is more prominent in CF (conflicting interests) games than in $\mathrm{CM}$ (common interests) games. An increase in the inequality ratio has different effects in $\mathrm{CM}$ and $\mathrm{CF}$ games: In $\mathrm{CM}$, increasing inequality makes it more likely that the subjects choose the action corresponding to the inefficient but equitable NE and hence reduces efficient coordination. In $\mathrm{CF}$, on the other hand, high inequality increases the choice of the action corresponding to the efficient but inequitable NE and increases efficient coordination in the redistribution treatment. In the redistribution treatment, the average transfer amount is significantly positive, and as expected, it is mostly player 1 who makes positive transfer. Whether player 1 makes positive transfer or not depends crucially on player 2's action choice, and both the size of transfer and the frequency of positive transfer are higher when player 2 chooses the action that corresponds to the efficient NE. On the other hand, increasing inequality increases the size of transfer but not the frequency of positive transfer. As a result, we also make the following findings regarding efficiency, as measured by the sum of the pair's payoffs, and equity, as measured by the ratio of their post-redistribution payoffs: The presence of the redistribution stage raises efficiency in $\mathrm{CF}$ games, and raises equity in both $\mathrm{CF}$ and $\mathrm{CM}$ games. Interestingly, we find that the increase in efficiency is due almost entirely to the increase in role 2's payoff.

The paper is organized as follows. The next section discusses the related literature. The inequality game and the different treatments are described in Section 3. Section 4 describes the experimental design, and Section 5 presents the analysis. The motive behind the positive transfer and the rationality of the subjects' choices are discussed in Section 6. We conclude in Section 7.

\section{Related Literature}

The present paper is related to a few strands of literature as follows.

As discussed above, our primary focus is on the strategic interaction between highly asymmetric players. In the experimental literature, effects on behavior of player asymmetry is studied extensively in the context of public good games. Asymmetry is introduced either in the level of the individual return (MPCR - marginal per capita return) of investment into the public good, or in the level of initial endowment (income) of each individual. The main focus in both cases is how the perception of inequality affects the individual and aggregate contribution levels. The findings are inconclusive. Buckley and Croson (2006) study a linear public good game played by a group of high- and low-income subjects, and find that the low-income subjects give a higher percentage of their income to the public good than the high-income subjects. Hofmeyr et al. (2007) find that heterogeneity has no impact on the contribution and the poor and rich players contribute the same proportion of their 
endowments. Anderson et al. (2008) examine the effect of revealing information about inequality in the show-up fees for their subjects, and find that making it public substantially reduces contribution levels. Oxoby and Spraggon (2013) find that heterogeneity significantly reduces contributions to the public good in their public good experiment with different income levels. Maurice et al. (2013) have their subjects play the public good game under both equal and unequal endowments, and study how their individual contributions adjust to the circumstances. ? study a public good game played by rich players in the presence of poor non-active players who benefit from the good. ${ }^{2}$

There are also public good game experiments with unequal incomes and redistribution. Uler (2011) studies a public good game with ex post redistribution of income by exogenously specifying the tax rates. When the initial income distribution is unequal, Uler (2011) finds that increasing the tax rates aimed at a more equal distribution ex post increases contribution to the public good. Belafoutas et al. (2013) let the subjects choose the redistribution rate before the contribution decisions, and find that when inequality is a result of real effort, the subjects prefer the policy that entails less redistribution. While most public good experiments with heterogeneity in the literature use models in which each player has a dominant action of "no contribution," exceptions are Chan et al. (1996, 1999), who study nonlinear public good games with multiple (interior) equilibria. Instead of examining coordination, however, Chan et al. (1996) focus on a particular equilibrium with certain properties, and study how the observed contributions by the rich and poor subjects differ from the equilibrium prediction. ${ }^{3}$

The present paper differs from the heterogeneous public good experiments in the literature in a few important ways. First, to the best of our knowledge, there is no public good game experiment that involves voluntary redistribution of payoffs ex post. Second, as mentioned above, most public good games studied in the literature have a dominant action of "no contribution," and hence are fundamentally different from the coordination games studied in this paper.

In our inequality game with the redistribution stage, the poor player 2's action that corresponds to the efficient equilibrium is similar to the sender's action of trusting money to the receiver in the well-known trust game. In both cases, it yields benefits to the other player and also implies a higher aggregate payoff. ${ }^{4}$ The trust games played by asymmetrically endowed players are studied by some authors. Among them, Hargreaves Heap et al. (2013) study the effect of endowment inequality on the agerage trust and return rates, and find that inequality has little impact on

\footnotetext{
${ }^{2}$ Tavoni et al. (2011) also find that inequality in endowments makes the provision of public goods difficult in their threshold public good game, but also find that the problem can be mitigated by the introduction of the pre-play communication ("pledge") phase which works as a coordination device.

${ }^{3}$ Chan et al. (1999) study the interactions of heterogeneity and communication.

${ }^{4}$ According to Camerer (2003), the average return to the sender in various trust game experiments can be higher or lower than the amount trusted.
} 
the average trust rate, but has a negative impact on the return rate through the less trustworthy behavior of the rich subjects. ${ }^{5}$ Different from the trust game, our experiment has player 1 also make an initial action choice, enabling us to examine the interplay between the strategic interactions and the redistribution motive.

Voluntary redistribution following a strategic interaction is discussed in the context of the real-effort experiments. Erkal et al. (2011) conduct an experiment on a real-effort tournament game with a redistribution stage by a group of four players. Erkal et al. (2011) find that the first-ranked subjects give significantly less than the second-ranked subjects to other members of their group, and attribute this finding to the propensity of subjects with self-regarding preferences to rank first by working harder than subjects with other-regarding preferences. ${ }^{6}$

The relationship between the presence of inequality and the preference for redistribution in the form of tax policies has been the subject of several experiments. Through the elicited preferences for redistribution rules, Rutström and Williams (2000) find that their subjects' preferences for redistribution under inequality are best described by self-interest, whereas Tyran and Sausgruber (2006) find that voting behavior under inequality is best explained by the inequality aversion hypothesis. Krawczyk (2010) increases dispersion in the probability that each subject wins a prize, and finds no significant increase in the ex ante preference for redistribution when those probabilities are exogenously specified. In their experiment with large inequality, Durante et al. (2014) let the tax rate chosen by one randomly selected individual, and find that the individual chooses a higher tax rate when he/she knows his/her relative position in the income distribution. Agranov and Palfrey (2015) find that higher inequality in productivity induces the suggestion of higher redistribution policies.

The primary focus of the extensive literature on coordination game experiments is on the comparison between payoff dominance and risk dominance as the effective predictor of the outcome of subjects' play. Cooper et al. (1990, 1992), Straub (1995), Van Huyck et al. (1990), Goeree and Holt (2005), among others, observe that risk dominance predicts subjects' play better than payoff dominance. ${ }^{7}$ We avoid the issue of payoff dominance versus risk dominance by specifying payoffs so that the efficient equilibrium, which maximizes the sum of the two players' payoffs, is also risk

\footnotetext{
${ }^{5}$ Greiner et al. (2012) study a dynamic game in which the subjects are randomly matched to play the trust game over multiple rounds. They find that the growth rate of the aggregate endowment decreases rapidly when the subjects' initial endowments are the same, but is more stable when they endowments are different.

${ }^{6}$ Ohtake et al. (2013) find to the contrary that the first-ranked subjects give more than the second-ranked subjects in their real-effort experiment.

${ }^{7}$ Van Huyck et al. (1990) observe that a coordination failure can result from the introduction of a dominated action which yields the efficient outcome. Goeree and Holt (2005) observe the sensitivity of the coordination rates to the detailed payoff specification. Furthermore, Van Huyck et al. (1990) and Goeree and Holt (2005) both find that the increased number of players makes coordination more difficult. This observation leads them to the conclusion that risk dominance is a more effective criterion.
} 
dominant. Furthermore, we control for the level of risk dominance of the efficient equilibrium across different games so that risk dominance will not be a factor in our analysis. To the best of our knowledge, there exists no coordination game experiment in the literature that studies the effect of payoff asymmetry between the players. ${ }^{8}$ One important feature of our experiment is that the subjects' roles are fixed throughout the experimental sessions. In other words, once a subject is assigned the advantageous role (role 1) or disadvantageous role (role 2) at the beginning of each session, their role stays the same until the end of the session. This design is intended to mimic the persistence of inequality in reality, and also to avoid the type of (indirect) reciprocity that a role 1 subject who received transfer as a role 2 player earlier in the session rewards his current role 2 partner to return the favor. ${ }^{9}$

In summary, this paper presents a departure from the literature with the combination of the following features:

- Strategic interaction under inequality.

- Voluntary ex post redistribution of payoffs.

- Coordination games with a efficiency-equity trade-off.

\section{Models of Inequality and Redistribution}

\subsection{Inequality Games}

Formally, an inequality game $G$ is a $2 \times 2$ coordination game: Each player $i$ chooses his action $x_{i}$ from the set $\{0,1\}$, and their payoff functions are given by

$$
\begin{aligned}
& u_{1}(x)=a x_{1} x_{2}+b\left(1-x_{1}\right)+c_{1}\left(1-x_{2}\right), \\
& u_{2}(x)=a x_{1} x_{2}+b\left(1-x_{2}\right)+c_{2}\left(1-x_{1}\right) .
\end{aligned}
$$

For the interpretation of these payoff functions, suppose that the players engage in the production of a public good. Each player $i$ either makes effort $x_{i}=1$ or not $x_{i}=0$ toward the production of the good. The public good is produced if and only if both players make effort, and when produced, it generates utility $a$ to each one of them. On the other hand, each player $i$ has two outside options that are affected by one's own and the other's action choices as follows: When player $i$ makes effort, it entails a personal opportunity cost equal to $b$. On the other hand, when $i$ makes effort, it inflicts negative externalities on player $j$, and destroys the latter's outside option which is worth $c_{j}$. We can for example suppose that $i$ 's production effort generates nuisance that prevents $j$ from deriving utility from his alternative activity.

\footnotetext{
${ }^{8}$ Crawford et al. (2008) investigate the effect of payoff difference between the two players in the battle of the sexes games and find that increasing the difference reduces the likelihood of coordination. However, their games are symmetric in the sense that one player's payoff in the first coordination profile equals the other player's payoff in the second coordination profile.

${ }^{9}$ Note that a subject faces a different subject in every round according to the random matching format.
} 
We suppose that the parameters satisfy

$$
a>b>0 \text { and } c_{1}>c_{2}>0 .
$$

Note that the second condition is the only source of inequality between the two players: the value of player 1's outside option vulnerable to negative externalities from 2's effort is higher than the value of player 2's corresponding option. Writing $X$ for no effort $x_{i}=0$, and $Y$ for effort $x_{i}=1$, we can depict the payoff table as in Figure 1.

\begin{tabular}{c|cc|cc}
$\mathrm{P} 1 \backslash \mathrm{P} 2$ & \multicolumn{2}{|c|}{$X$} & \multicolumn{2}{|c}{$Y$} \\
\hline$X$ & $b+c_{1}$ & $b+c_{2}$ & $b$ & $c_{2}$ \\
\hline$Y$ & $c_{1}$ & $b$ & $a$ & $a$
\end{tabular}

Figure 1: Inequality Game: $c_{1}>c_{2}$

Since $a>b>0$, both $(X, X)$ and $(Y, Y)$ are pure NE. We also assume:

- $c_{1}+c_{2}>2(a-b) \Leftrightarrow(X, X)$ uniquely maximizes the sum of payoffs.

- $\quad c_{1}>b>c_{2} \quad \Leftrightarrow u_{1}(x)>u_{2}(x)$ for $x \neq(Y, Y)$.

- $\quad 2 b>a \Leftrightarrow(X, X)$ is risk dominant.

It follows from the second condition that $(Y, Y)$ is the only profile in which the two players earn the same payoff. We further restrict attention to the following subclasses of inequality games: An inequality game has common-interest $(C M)$ if $b+c_{1}>b+c_{2}>a$, and has conflicting-interest $(C F)$ if $b+c_{1}>a>b+c_{2}$. In other words, if an inequality game has $\mathrm{CM}$, then both players 1 and 2 prefer the $\mathrm{NE}(X, X)$ to the NE $(Y, Y)$, whereas if it has $\mathrm{CF}$, then player 1 prefers $(X, X)$ to $(Y, Y)$ and player 2 prefers $(Y, Y)$ to $(X, X)$.

\subsection{Voluntary Redistribution}

Our main focus is on the subjects' behavior in the inequality game with and without the ex post redistribution stage in which both players may transfer their payoffs earned from playing the game to the other player. Let $g_{i}$ denote player $i$ 's final payoff after the possible redistribution of their payoffs. First, in the baseline treatment, no redistribution takes place after the play of the inequality game $G$.

T1: No Redistribution: The players' final payoffs equal their payoffs from $G: g_{i}=$ $u_{i}$.

In the redistribution treatment, the players may give part or all of their payoffs to the other player after the play of the inequality game. 
T2: Voluntary Redistribution: After the players play $G$, they publicly observe the actions and payoffs, and then determine how much of their payoff points to give to the other player. If player $i$ chooses to give $t_{i}\left(\leq u_{i}\right)$ payoff points to player $j(i \neq j)$, then the final payoffs are given by

$$
g_{1}(x)=u_{1}(x)-t_{1}+t_{2}, \quad \text { and } \quad g_{2}(x)=u_{2}(x)-t_{2}+t_{1} .
$$

Clearly, if the players are simple payoff maximizers, then no redistribution of payoffs takes place in any SPE of T2, and hence the only SPE payoff profiles of these games are the NE payoff profiles of $G$. If redistribution takes place, on the other hand, then it may be a consequence of the subjects' social preferences such as inequality aversion, or their tendency to reciprocate the other's behavior. In order to better understand their preferences, we also include a game form in which the final allocation is determined by one of the players as follows.

T0: Dictator Decision: One player in each pair makes a choice among four payoff pairs that correspond to the four cells of the payoff table.

\section{Experimental Design}

The experiments were conducted at the Experimental Economics Laboratory at the ISER, Osaka University, with the subjects recruited from undergraduate and graduate students of Osaka University of various majors. There were six sessions with a total of 124 subjects (four sessions of 20 subjects and two sessions of 22 subjects). No subject attended more than one session. The subjects in each session were divided randomly into two groups of the same size with the first group of subjects assigned the role of player 1 , and the second group of subjects assigned the role of player 2. The player roles stay the same throughout the session. The role assignment is done privately on the PC screen in front of each subject. The instruction presents the equation (1) that generates the payoffs, and provides illustration of the equation by means of numerical examples and graphs. ${ }^{10,11}$ The payoff matrix is also shown on the PC screen in front of each subject. At the end of each session, the earning of a subject is computed from the sum of his/her payoff points during the session with the conversion rate of 1 payoff point to JPY1.3. The average earnings are JPY9946.1 for the role 1 subjects and JPY3122.8 for the role 2 subjects. ${ }^{12}$

In each session, each subject faces inequality games with six different payoff tables: CM2, CM4 and CM6 are CM inequality games, and CF2, CF4 and CF6 are

\footnotetext{
${ }^{10}$ The program was coded using z-tree (Fischbacher (2007)). We also had five other sessions with 106 subjects in which no information about the underlying utility function (1) is revealed. This paper focuses on the treatment with the information.

${ }^{11}$ See the Appendix for an English translation of the instruction.

${ }^{12}$ These translate to about US\$90-127 for role 1 and US\$28-40 for role 2 according to the exchange rates at the time of the experiments.
} 
$\mathrm{CF}$ inequality games. The suffix represents the inequality ratio between the players as measured by the payoff ratio at $(X, X)$ :

$$
\frac{u_{1}(X, X)}{u_{2}(X, X)}=k \text { in } \mathrm{CF} k \text { and } \mathrm{CM} k \text {. }
$$

We set

$$
a=100, \quad \text { and } \quad b=60
$$

in all six games, and vary $c_{i}$ as in Table 1 . The resulting payoff tables are depicted in Figures 2 and 3. Note that all CM games are the same in terms of player 2's payoffs, and so are all CF games. Furthermore, since $a$ and $b$ remain unchanged in all games, so is the risk dominance level of $(X, X)$.

\begin{tabular}{c|c|c|c|c|c|c} 
& CF2 & CF4 & CF6 & CM2 & CM4 & CM6 \\
\hline$c_{1}$ & 100 & 260 & 420 & 160 & 380 & 600 \\
$c_{2}$ & 20 & 20 & 20 & 50 & 50 & 50
\end{tabular}

Table 1: Parameter Specifications

\begin{tabular}{c|c|cc|c|cc|c|c} 
& $X$ & $Y$ & & $X$ & $Y$ & & $X$ & $Y$ \\
\hline$X$ & 220,110 & 60,50 & $X$ & 440,110 & 60,50 & $X$ & 660,110 & 60,50 \\
$Y$ & 160,60 & 100,100 & $Y$ & 380,60 & 100,100 & $Y$ & 600,60 & 100,100
\end{tabular}

CM2

CM4

CM6

\begin{tabular}{|c|c|c|c|c|c|c|c|c|}
\hline & $X$ & $Y$ & & $X$ & $Y$ & & $X$ & $Y$ \\
\hline$X$ & 160,80 & 60,20 & $X$ & 320,80 & 60,20 & $X$ & 480,80 & 60,20 \\
\hline$Y$ & 100,60 & 100,100 & $Y$ & 260,60 & 100,100 & $Y$ & 420,60 & 100,100 \\
\hline
\end{tabular}

Figure 2: CM inequality games

CF2

CF4

CF6

Figure 3: CF inequality games

Each session consists of three different blocks that correspond to the three treatments T0-T2 of our main interest as described above. Each block in turn consists of six rounds that correspond to the six inequality games CF2-CF6 and CM2-CM6. In all four sessions, the ordering of the blocks is fixed and given by

$$
\mathrm{T} 0 \rightarrow \mathrm{T} 1 \rightarrow \mathrm{T} 2 \cdot^{13}
$$


The six games appear in random order in the six rounds of each block. In the T0 treatment, one subject in each pair is randomly chosen to make a choice. ${ }^{14}$ After the outcome of play is shown on the $\mathrm{PC}$ screen, anonymous rematching takes place in the stranger format.

\section{Analysis}

Our analysis examines the effects of game forms (T0, T1, and T2), payoff structure $(\mathrm{CM}$ and $\mathrm{CF})$, player roles ( 1 and 2$)$, and inequality ratios $(k=2,4,6)$ on the action choice, coordination rates, the frequency and size of transfers, and the efficiency and equity of the final outcome.

\subsection{Social preferences in the dictator treatment (T0)}

We begin by examining the outcome of the dictator treatment (T0) to understand the possibility that the subjects are maximizers of some social preferences rather than their own payoffs. Specifically, we regard the following three types of social preferences as particularly relevant to their action choice in the present environment.

1. Inequality Aversion (IQA: prefers equitable allocations)

2. Inefficiency Aversion (IEA: prefers efficient allocations)

3. Spite/Altruism (SA: prefers reducing or raising the other's allocation)

Figure 4 shows the frequency of each of four choices $(A, B, C, D)$ for $\mathrm{CM}$ and CF games. ${ }^{15}$ As seen, the subjects' choices are almost entirely limited to $A$ and $D$, which are NE of the game. ${ }^{16}$ Additionally, the role 1 subjects choose $A$ more than $94 \%$ of the time, whereas the choice of the role 2 subjects is approximately reversed depending on whether the game is $\mathrm{CM}$ or $\mathrm{CF}$. In $\mathrm{CM}$, they choose $A$ more than $90 \%$ of the time, whereas in most cases of $\mathrm{CF}$, they choose $D$ on average $80 \%$ of the time. ${ }^{17}$ The inequality ratio $k$ is mostly insignificant in both $\mathrm{CM}$ and $\mathrm{CF} .{ }^{18}$

\footnotetext{
${ }^{13}$ Based on the results from the preliminary sessions, we fixed the order of the treatments because of the concern that the subjects would read into our intention if they experienced T2 before T1. Each session had one additional treatment T3 which is not discussed in this paper. Since T3 was given at the end of each session, it didn't affect the subjects' behavior in the earlier treatments.

${ }^{14}$ Once a subject is chosen, he makes a choice in all six rounds of the T0 treatment (against different opponents).

${ }^{15}$ The outcome in T0 is denoted as $A=(X, X), B=(X, Y), C=(Y, X)$, and $D=(Y, Y)$.

${ }^{16}$ The hypothesis that the four outcomes are randomly chosen with equal probabilities is rejected $(p=0.01)$.

${ }^{17} \mathrm{~A}$ multinomial logit regression over the four outcomes is no more informative than the descriptive statistics because of the skewed distribution of the choice data.

${ }^{18}$ The unique exception is the choice by the role 2 subjects who choose $D$ less often in CF4 than in CF2 (Mann-Whitney U-test, $p=0.1$ ).
} 


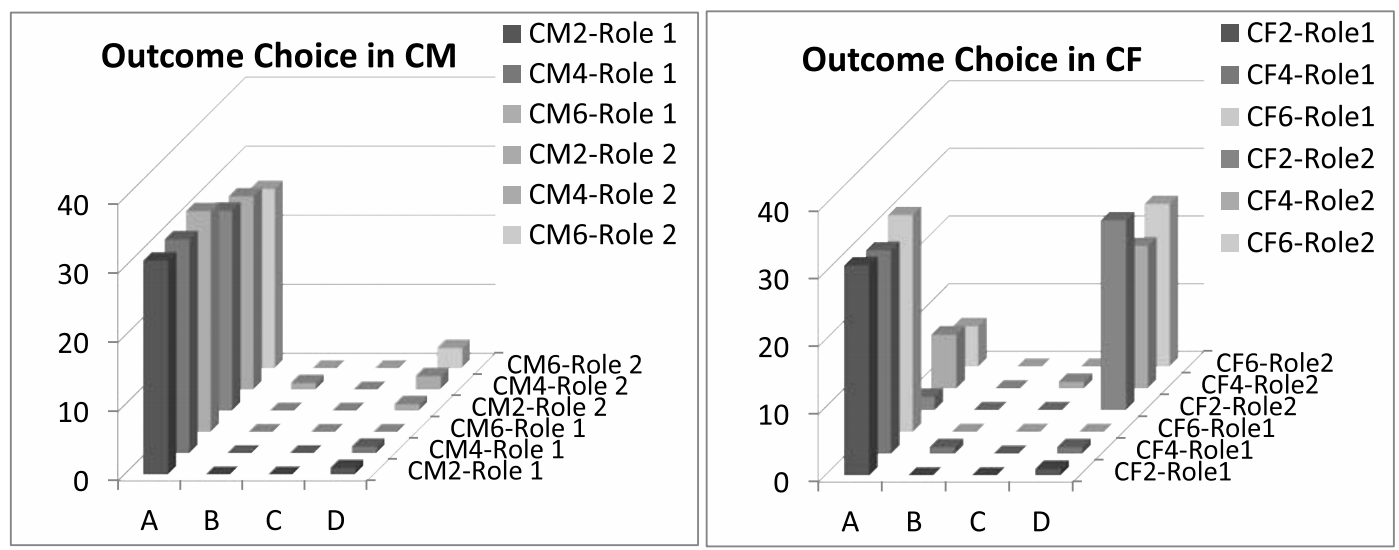

Figure 4: Outcome distribution in T0

For the role 1 subjects, their choice of $A$ is consistent with both own payoff maximization and IEA, whereas for the role 2 subjects, their choice of $A$ in $\mathrm{CM}$ and $D$ in $\mathrm{CF}$ is consistent with own payoff maximization. Even for the role 2 subjects, however, they have a weak tendency to choose $A$ more often in CF when $k$ is larger. This may indicate role 2's concern about the decrease in role 1's payoff resulting from 2's choice of D instead of A, and hence suggests an element of IEA/altruism in their behavior.

Observation 1 (Single-person decision) The behavior of the role 1 subjects in TO is consistent with own payoff maximization and IEA. The behavior of the role 2 subjects in TO is consistent with own payoff maximization, but has a degree of IEA or altruism.

\subsection{What influences the action choice?}

Figure 5 shows the number and frequency of each action ( $X$ and $Y$ ) by the game form (T1 and T2), payoff structure (CM and $\mathrm{CF}$ ), and subject roles (1 and 2). As seen, there is a significant difference in the subjects' action choice between $\mathrm{T} 1$ and $\mathrm{T} 2$, and the difference is more prominent in CF. Role 2 subjects choose $X$ more often in $\mathrm{T} 2$ than in $\mathrm{T} 1$ for $\mathrm{CF}$ but not for $\mathrm{CM}$, while role 1 subjects do so for both $\mathrm{CF}$ and $\mathrm{CM}$. Both role 1 and role 2 subjects choose $Y$ more often in $\mathrm{CF}$ than in CM. This observation is confirmed by the random effects logit regressions in Table 2, where the dependent variable equals one if a subject chooses $Y$. Models (1) and (2) are for $\mathrm{CM}$ and $\mathrm{CF}$, respectively, and have as explanatory variables the subject role ('role' $=1$ for role 1$)$, the game form (' $\mathrm{t} 2$ ' $=1$ for $\mathrm{T} 2)$, the inequality ratio $\left({ }^{\prime} \mathrm{k}_{4}{ }^{\prime}=1\right.$ if $k=4$ and ' $\mathrm{k}_{6}$ '= 1 if $k=6$ ), the inverse ' 1 /round' of the round number within 


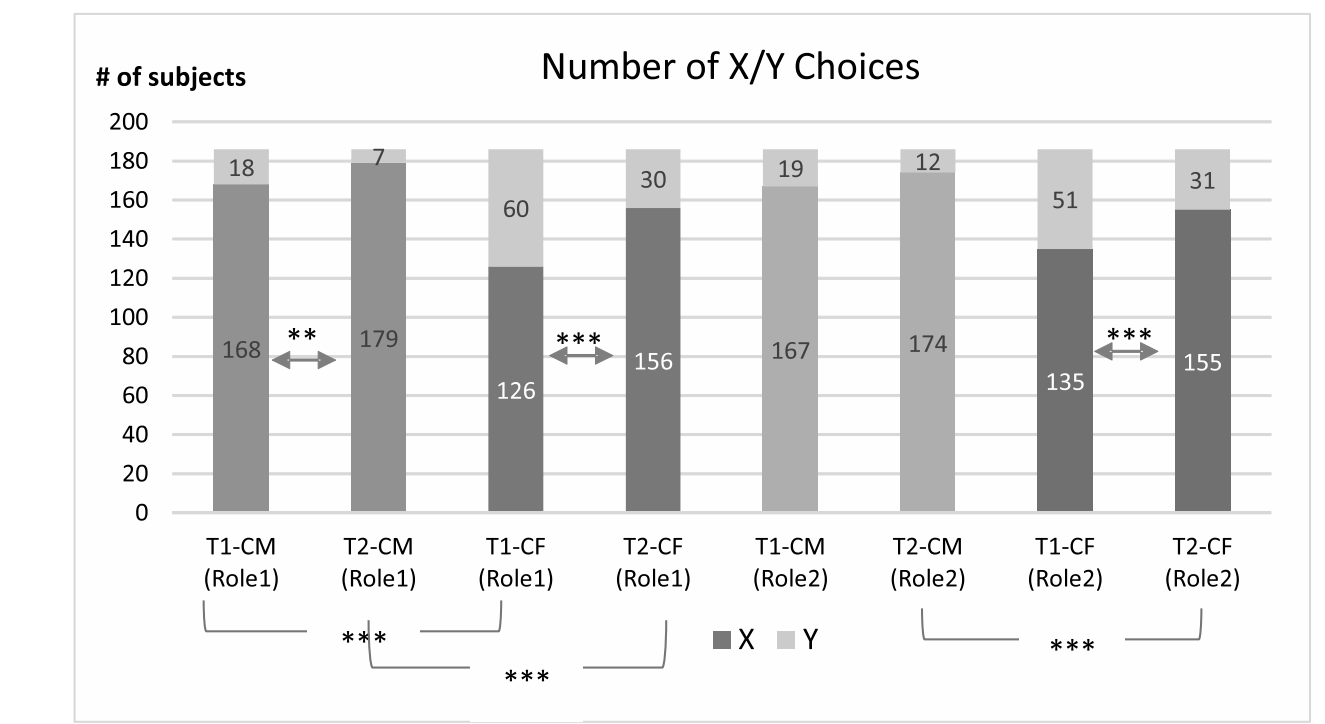

** and $* * *$ : significant difference at $5 \%$ and $1 \%$, respectively, between the respective pair of distributions ( $\chi^{2}$-test). Shown in each column are the numbers of each action choice aggregated for $k=2,4$, and 6 .

Figure 5: Action choices in T1 and T2

each treatment, as well as cross terms. ${ }^{19}$ Models (3) and (4) aggregate the data from $\mathrm{CM}$ and $\mathrm{CF}$ and have as explanatory variables the payoff structure (' $\mathrm{cf}$ ' $=1$ if $\mathrm{CF}$ ) and the cross term between the subject role and payoff structure ('cf $*$ role').

We see that the coefficient for ' $t 2$ ' is significantly negative in model (2), suggesting that CF-T2 induces action $X$ significantly more often than CF-T1. On the other hand, no significant effect of T2 is observed in CM in model (1). The coefficient for the cross term 'role * t2' is insignificant in both models (1) and (2), implying that these effects of T2 are independent of the subject role. Models (1) and (2) also show no significant effect of the subject role on the action choice in $\mathrm{CM}$ and $\mathrm{CF}$ : 'role' is not significant by itself, and neither are the cross variables involving 'role'. ${ }^{20}$ Models (3) and (4) show that the subjects choose $Y$ more often in CF than in $\mathrm{CM}$, irrespective of the subject role. They also show the different effects of the inequality ratio $k$ in $\mathrm{CM}$ and $\mathrm{CF}$ : In both $\mathrm{CM}-\mathrm{T} 1$ and $\mathrm{CM}-\mathrm{T} 2$, higher inequality overall has a positive impact on the choice of $Y$, and the positive effect is significant when $k=6$. Also in CF-T1, high inequality $(k=6)$ increases the choice of $Y$, whereas increased inequality has a significantly positive impact on the choice of $X$ in CF-T2. ${ }^{21}$ The observation on the action choice can be summarized as follows:

\footnotetext{
${ }^{19}$ The round number is inversed so that it takes values between 0 and 1: This helps us with the regressions in which other regressors are binomial and equal to 0 or 1 .

${ }^{20}$ In model (3), ' $r o l e{ }^{*} k_{4}$ ' is (weakly) significant, while ' $r o l e^{*} k_{4}$ ' is not.

${ }^{21}$ In model (3), ' $\mathrm{k}_{6}$ ' is significantly positive and ' $c \mathrm{f}^{*} \mathrm{k}_{6}$ ' is significantly negative. However, ' $\mathrm{k}_{6}$ ' is
} 


\begin{tabular}{|c|c|c|c|c|}
\hline Model & (1) & (2) & (3) & (4) \\
\hline Condition & $\mathrm{CM}$ & $\mathrm{CF}$ & $\mathrm{T} 1$ & $\mathrm{~T} 2$ \\
\hline role & $\begin{array}{l}-0.33 \\
(0.95)\end{array}$ & $\begin{array}{c}0.27 \\
(0.57)\end{array}$ & $\begin{array}{c}-0.36 \\
(0.69)\end{array}$ & $\begin{array}{c}-0.53 \\
(0.81)\end{array}$ \\
\hline $\mathrm{t} 2$ & $\begin{array}{l}-0.75 \\
(0.59)\end{array}$ & $\begin{array}{c}-0.94^{* * *} * \\
(0.32)\end{array}$ & & \\
\hline role*t2 & $\begin{array}{l}-0.69 \\
(0.74)\end{array}$ & $\begin{array}{l}-0.45 \\
(0.46)\end{array}$ & & \\
\hline $\mathrm{k}_{4}$ & $\begin{array}{c}0.67 \\
(0.51)\end{array}$ & $\begin{array}{l}-0.51 \\
(0.40)\end{array}$ & $\begin{array}{c}0.51 \\
(0.55)\end{array}$ & $\begin{array}{c}0.92 \\
(0.83)\end{array}$ \\
\hline $\mathrm{k}_{6}$ & $\begin{array}{c}1.24^{* *} \\
(0.60)\end{array}$ & $\begin{array}{l}-0.07 \\
(0.41)\end{array}$ & $\begin{array}{c}1.06^{* *} \\
(0.52)\end{array}$ & $\begin{array}{c}1.74^{* *} \\
(0.74)\end{array}$ \\
\hline role $^{*} k_{4}$ & $\begin{array}{c}0.48 \\
(0.89)\end{array}$ & $\begin{array}{c}0.77 \\
(0.56)\end{array}$ & $\begin{array}{l}0.94^{*} \\
(0.57)\end{array}$ & $\begin{array}{l}-0.06 \\
(0.74)\end{array}$ \\
\hline role $^{*} \mathrm{k}_{6}$ & $\begin{array}{c}0.21 \\
(0.98)\end{array}$ & $\begin{array}{l}-0.45 \\
(0.59)\end{array}$ & $\begin{array}{c}-0.09 \\
(0.58)\end{array}$ & $\begin{array}{l}-0.45 \\
(0.69)\end{array}$ \\
\hline $\mathrm{cf}$ & & & $\begin{array}{c}2.29 * * * \\
(0.55)\end{array}$ & $\begin{array}{c}2.76^{* * *} \\
(0.84)\end{array}$ \\
\hline role*cf & & & $\begin{array}{c}0.36 \\
(0.63)\end{array}$ & $\begin{array}{c}0.58 \\
(0.74)\end{array}$ \\
\hline $\mathrm{cf}^{*} \mathrm{k}_{4}$ & & & $\begin{array}{l}-0.87 \\
(0.59)\end{array}$ & $\begin{array}{c}-1.41^{*} \\
(0.75)\end{array}$ \\
\hline $\mathrm{cf}^{*} \mathrm{k}_{6}$ & & & $\begin{array}{l}-1.00^{*} \\
(0.54)\end{array}$ & $\begin{array}{c}-2.20^{* * *} \\
(0.81)\end{array}$ \\
\hline $1 /$ round & $\begin{array}{c}0.74 \\
(0.61)\end{array}$ & $\begin{array}{c}0.00 \\
(0.43)\end{array}$ & $\begin{array}{c}0.12 \\
(0.42)\end{array}$ & $\begin{array}{c}-0.15 \\
(0.52)\end{array}$ \\
\hline constant & $\begin{array}{c}-4.66^{* * *} \\
(0.75)\end{array}$ & $\begin{array}{c}-1.31^{* * * *} \\
(0.47)\end{array}$ & $\begin{array}{c}-3.59 * * * \\
(0.53) \\
\end{array}$ & $\begin{array}{c}-4.79^{* * *} \\
(0.93) \\
\end{array}$ \\
\hline Observations & 744 & 744 & 744 & 744 \\
\hline Log-likelihood & -162.84 & -339.26 & -315.38 & -213.50 \\
\hline
\end{tabular}

Table 2: Random effect logit regressions of action choice: $y=\mathbf{1}_{\left\{a_{i}=Y\right\}}$

Observation 2 (Action choice)

1. In both $T 1$ and T2, the subjects choose $X$ significantly less often in $C F$ than in $C M$.

2. In CF, the subjects choose $X$ significantly more often in T2 than in T1.

3. The subject role has no significant impact on the action choice in $C M$ and $C F$.

4. High inequality $(k=6)$ increases the choice of $Y$ in both CM-T1 and CMT2. High inequality also increases the choice of $Y$ in CF-T1, but increases the choice of $X$ in CF-T2.

more significant (at $5 \%$ ) than ' $\mathrm{cf}^{*} \mathrm{k}_{6}$ ' (at $10 \%$ ), implying the positive impact of $k=6$ on the choice of $Y$. Similar reasoning implies the positive impact of inequality on the choice of $X$ in CF-T2 in model (4). 
Our central observation is Observation 2.2 on the comparison between T1 and $\mathrm{T} 2$, which cannot be explained by the maximization of self-regarding utility. The insignificance of the player role in $\mathrm{CF}$ in Observation 2.3 is in sharp contrast with our observation in T0, where the dominant choice is $A=(X, X)$ for role 1 and $D=(Y, Y)$ for role $2 .{ }^{22}$

\subsection{What influences the frequency of coordination?}

\begin{tabular}{|c|c|c|c|c|c|c|c|c|}
\hline \multirow{3}{*}{ action profile } & \multicolumn{4}{|c|}{$\mathrm{CM}$} & \multicolumn{3}{|c|}{$\mathrm{CF}$} & \multirow{3}{*}{$\mathrm{T} 2$} \\
\hline & \multicolumn{2}{|c|}{ T0 } & \multirow[t]{2}{*}{$\mathrm{T} 1$} & \multirow[t]{2}{*}{$\mathrm{T} 2$} & \multicolumn{2}{|c|}{ T0 } & \multirow[t]{2}{*}{$\mathrm{T} 1$} & \\
\hline & Role 1 & Role 2 & & & Role 1 & Role 2 & & \\
\hline$(X, X)$ & 94 & 83 & 151 & 167 & 93 & 16 & 89 & 130 \\
\hline$(Y, Y)$ & 2 & 6 & 2 & 0 & 2 & 73 & 14 & 5 \\
\hline$(X, Y)$ & 0 & 1 & 17 & 12 & 1 & 0 & 37 & 26 \\
\hline$(Y, X)$ & 0 & 0 & 16 & 7 & 0 & 1 & 46 & 25 \\
\hline \multicolumn{9}{|c|}{$p$-value $\left(\chi^{2}\right.$ test $):$} \\
\hline $\mathrm{T} 0=\mathrm{T} 1=\mathrm{T} 2$ & 0.00 & 0.00 & & & 0.00 & 0.00 & & \\
\hline $\mathrm{T} 1=\mathrm{T} 2$ & & & 0.07 & & & & 0.00 & \\
\hline $\mathrm{CM}=\mathrm{CF}$ & & 0.00 & 0.00 & 0.00 & & & & \\
\hline
\end{tabular}

The three lines in the bottom report the $p$-values of the $\chi^{2}$ tests of the hypothesis that the distributions are the same for T0-T2 (first line), between T1 and T2 (second line), and between $\mathrm{CM}$ and $\mathrm{CF}$ (third line)

Table 3: Realization of action profiles

Table 3 describes the realized distribution of four action profiles in T0 through T2. While the difference among T0-T2 is strongly significant in both CM and $\mathrm{CF}$, the difference between $\mathrm{T} 1$ and $\mathrm{T} 2$ is strongly significant only in $\mathrm{CF}$ and only weakly significant in CM $(p=0.07)$. The difference between CM and CF is strongly significant in $\mathrm{T} 0, \mathrm{~T} 1$ and $\mathrm{T} 2$.

Tables 4 and 5 present logit regressions of action profiles. Table 4 separates data from $\mathrm{CM}$ and $\mathrm{CF}$ and examines the effect of the inequality ratio (' $\mathrm{k}_{4}$ ' and ' $\mathrm{k}_{6}$ '), and the game form ('t2'). Table 5 combines data from CM and CF and examines the effect of the game form ('t2') and the payoff structure ('cf'). In each table, the first model has total coordination $\left(\mathbf{1}_{\{a=(X, X) \text { or }(Y, Y)\}}\right)$ as the dependent variable, whereas the second model is a multinomial regression using one of the coordination profiles $(X, X)$ as the base. ${ }^{23}$ We look at the effect of each explanatory variable separately.

On the inequality ratio $k$, we note that ' $\mathrm{k}_{4}$ ' or ' $\mathrm{k}_{6}$ ' in models (1) and (3) in Table 4 has a significant impact on the rates of total coordination for both $\mathrm{CM}$ and $\mathrm{CF}$.

\footnotetext{
${ }^{22}$ In addition to some role 2 subjects who switch from $D$ in T0 to $X$ in CF-T1 or CF-T2, there are also some role 1 subjects who switch from $A=(X, X)$ in T0 to $Y$ in CF-T1 or CF-T2.

${ }^{23}$ We choose $(X, X)$ as the outcome base since the distribution of action profiles is skewed toward $(X, X)$. The multinomial analysis is feasible only with this choice of a base.
} 


\begin{tabular}{|c|c|c|c|c|c|c|c|c|}
\hline \multirow{3}{*}{$\begin{array}{l}\text { Model } \\
\text { Dep. var. }\end{array}$} & \multicolumn{4}{|c|}{$\mathrm{CM}$} & \multicolumn{4}{|c|}{$\mathrm{CF}$} \\
\hline & $(1)$ & & (2) & & $(3)$ & & (4) & \\
\hline & $\mathbf{1}_{\{(X, X) \text { or }(Y, Y)\}}$ & $\mathbf{1}_{\{(Y, X)\}}$ & $\mathbf{1}_{\{(X, Y)\}}$ & $\mathbf{1}_{\{(Y, Y)\}}$ & $\mathbf{1}_{\{(X, X) \text { or }(Y, Y)\}}$ & $\mathbf{1}_{\{(Y, X)\}}$ & $\mathbf{1}_{\{(X, Y)\}}$ & $\mathbf{1}_{\{(Y, Y)\}}$ \\
\hline $\mathrm{t} 2$ & $\begin{array}{l}1.05^{*} \\
(0.55)\end{array}$ & $\begin{array}{c}-15.05^{* * *} \\
(0.53)\end{array}$ & $\begin{array}{l}-0.07 \\
(0.86)\end{array}$ & -0.12 & $\begin{array}{c}0.80^{* * *} \\
(0.23)\end{array}$ & $\begin{array}{l}-0.62 \\
(0.52)\end{array}$ & $\begin{array}{c}-0.89^{* *} \\
(0.41)\end{array}$ & $\begin{array}{l}-0.19 \\
(1.10)\end{array}$ \\
\hline $\mathrm{k}_{4}$ & $\begin{array}{c}-0.79^{* *} \\
(0.36)\end{array}$ & $\begin{array}{c}0.23 \\
(0.66)\end{array}$ & $\begin{array}{l}1.11^{*} \\
(0.58)\end{array}$ & $\begin{array}{c}15.46^{* * *} \\
(0.70)\end{array}$ & $\begin{array}{c}0.23 \\
(0.21)\end{array}$ & $\begin{array}{c}0.27 \\
(0.46)\end{array}$ & $\begin{array}{l}-0.67 \\
(0.42)\end{array}$ & $\begin{array}{l}1.08 \\
(0.94)\end{array}$ \\
\hline $\mathrm{k}_{6}$ & $\begin{array}{c}-0.84^{* *} \\
(0.40)\end{array}$ & $\begin{array}{c}0.39 \\
(0.51)\end{array}$ & $\begin{array}{c}1.04 \\
(0.67)\end{array}$ & $\begin{array}{c}15.75^{* * *} \\
(1.32)\end{array}$ & $\begin{array}{c}0.69^{* * *} \\
(0.26)\end{array}$ & $\begin{array}{l}-0.51 \\
(0.53)\end{array}$ & $\begin{array}{l}-0.56 \\
(0.42)\end{array}$ & $\begin{array}{l}1.00 \\
(0.87)\end{array}$ \\
\hline $\mathrm{t} 2 * \mathrm{k}_{4}$ & $\begin{array}{c}0.10 \\
(0.68)\end{array}$ & $\begin{array}{c}14.16^{* * *} \\
(0.79)\end{array}$ & $\begin{array}{l}-0.91 \\
(1.03)\end{array}$ & $\begin{array}{c}-15.72^{* * * *} \\
(0.99)\end{array}$ & $\begin{array}{c}0.06 \\
(0.34)\end{array}$ & $\begin{array}{l}-0.68 \\
(0.83)\end{array}$ & $\begin{array}{c}0.44 \\
(0.72)\end{array}$ & $\begin{array}{l}-2.08 \\
(1.65)\end{array}$ \\
\hline $\mathrm{t} 2 * \mathrm{k}_{6}$ & $\begin{array}{l}-0.68 \\
(0.60)\end{array}$ & $\begin{array}{c}14.60^{* * *} \\
(0.75)\end{array}$ & $\begin{array}{l}-0.20 \\
(0.83)\end{array}$ & $\begin{array}{c}-15.43^{* * *} \\
(1.05)\end{array}$ & $\begin{array}{l}-0.02 \\
(0.33)\end{array}$ & $\begin{array}{l}-0.48 \\
(0.89)\end{array}$ & $\begin{array}{c}0.17 \\
(0.61)\end{array}$ & $\begin{array}{l}-1.35 \\
(1.14)\end{array}$ \\
\hline $1 /$ round & $\begin{array}{l}-0.45 \\
(0.42)\end{array}$ & $\begin{array}{c}1.04 \\
(0.74)\end{array}$ & $\begin{array}{l}-0.56 \\
(0.62)\end{array}$ & $\begin{array}{c}1.81 \\
(1.61)\end{array}$ & $\begin{array}{l}-0.13 \\
(0.29)\end{array}$ & $\begin{array}{c}0.40 \\
(0.48)\end{array}$ & $\begin{array}{l}-0.49 \\
(0.55)\end{array}$ & $\begin{array}{l}-0.95 \\
(0.87)\end{array}$ \\
\hline cons & $\begin{array}{c}2.78^{* * *} * \\
(0.45)\end{array}$ & $\begin{array}{c}-2.94^{* * *} * \\
(0.61)\end{array}$ & $\begin{array}{c}-2.74^{* * *} \\
(0.62)\end{array}$ & $\begin{array}{c}-20.51^{* * *} \\
(0.53)\end{array}$ & $\begin{array}{l}-0.02 \\
(0.34)\end{array}$ & $\begin{array}{c}-0.78^{* *} \\
(0.39)\end{array}$ & $\begin{array}{l}-0.33 \\
(0.39)\end{array}$ & $\begin{array}{c}-2.32^{\text {*** }} \\
(0.70)\end{array}$ \\
\hline \# of obs. & 372 & 372 & & & 37372 & 37372 & & \\
\hline Log-likelihood & -136.81 & -186.31 & & & -232.96 & -382.84 & & \\
\hline
\end{tabular}

Table 4: Logit and multinomial logit regressions of action profiles: $\mathrm{CM}$ and $\mathrm{CF}$

\begin{tabular}{|c|c|c|c|c|}
\hline Model & $(1)$ & & $(2)$ & \\
\hline Dep. var. & $\mathbf{1}_{\{(X, X) \text { or }(Y, Y)\}}$ & $\mathbf{1}_{\{(Y, X)\}}$ & $\mathbf{1}_{\{(X, Y)\}}$ & $\mathbf{1}_{\{(Y, Y)\}}$ \\
\hline t2 & $\begin{array}{c}0.68^{* *} \\
(0.33)\end{array}$ & $\begin{array}{c}-0.94^{* *} \\
(0.48)\end{array}$ & $\begin{array}{l}-0.45 \\
(0.39)\end{array}$ & $\begin{array}{c}-13.84^{* * *} \\
(0.73)\end{array}$ \\
\hline $\mathrm{cf}$ & $\begin{array}{c}-1.45^{* * *} \\
(0.28)\end{array}$ & $\begin{array}{c}1.62^{* * *} \\
(0.39)\end{array}$ & $\begin{array}{c}1.29 * * * \\
(0.33)\end{array}$ & $\begin{array}{c}2.46^{* * *} \\
(0.62)\end{array}$ \\
\hline $\mathrm{t} 2 * \mathrm{cf}$ & $\begin{array}{c}0.15 \\
(0.44)\end{array}$ & $\begin{array}{l}-0.06 \\
(0.56)\end{array}$ & $\begin{array}{l}-0.28 \\
(0.47)\end{array}$ & $\begin{array}{c}12.43^{* * *} \\
(0.92)\end{array}$ \\
\hline $1 /$ round & $\begin{array}{l}-0.40 \\
(0.31)\end{array}$ & $\begin{array}{c}0.94^{* * *} \\
(0.39)\end{array}$ & $\begin{array}{l}-0.40 \\
(0.41)\end{array}$ & $\begin{array}{l}-0.24 \\
(0.64)\end{array}$ \\
\hline constant & $\begin{array}{c}1.84^{* * *} \\
(0.29) \\
\end{array}$ & $\begin{array}{c}-2.68^{* * *} \\
(0.40) \\
\end{array}$ & $\begin{array}{c}-2.02^{* * *} \\
(0.33) \\
\end{array}$ & $\begin{array}{c}-4.23^{* * *} \\
(0.57) \\
\end{array}$ \\
\hline \# of obs. & 7744 & 744 & & \\
\hline Log-likelihood & -377.83 & -581.78 & & \\
\hline
\end{tabular}

Table 5: Logit and multinomial logit regressions of action profiles: All data 
However, it is interesting to observe that while increasing $k$ decreases coordination in CM, it tends to have the opposite effect in CF. It can be seen from Model (2) that the less coordination in CM for a higher $k$ is caused by a decrease in the efficient coordination $(X, X)$ and an increase in miscoordination $(X, Y) \cdot{ }^{24}$ On the other hand, model (4) shows that the positive impact of ' $\mathrm{k}_{6}$ ' in CF comes mainly from an increase in $(X, X) .{ }^{25}$

On the comparison between T1 and T2, models (1) and (3) in Table 4 show that T2 has a significant positive impact on coordination in $\mathrm{CM}(p<0.1)$, and strongly so in CF $(p<0.01)$. From models $(2)$ and $(4)$, it can be seen that this is associated with the negative impact of ' $t 2$ ' on the miscoordination profiles $((Y, X)$ in $\mathrm{CM}$ and $(X, Y)$ in $\mathrm{CF})$. The same observation can be made in model (1) in Table 5 that aggregates $\mathrm{CM}$ and $\mathrm{CF}$. In this case, ' $t 2$ ' has a positive impact on total coordination but a negative impact on inefficient coordination $(Y, Y)$ and miscoordination $(Y, X)$ (model (2)). ${ }^{26}$ In sum, the presence of a transfer opportunity in T2 significantly facilitates efficient coordination and reduces coordination failures. This tendency is common in $\mathrm{CM}$ and $\mathrm{CF}$.

On the comparison between $\mathrm{CM}$ and $\mathrm{CF}$, Table 5 shows that ' $\mathrm{cf}$ ' has a negative impact on total coordination (model (1)), but a positive impact on inefficient coordination $(Y, Y)$ and miscoordination profiles (model $(2)$ ). This holds for both $\mathrm{T} 1$ and $\mathrm{T} 2$ since the cross term ' $\mathrm{t} 2 * \mathrm{cf}$ ' is significant only for $(Y, Y)$ in model $(2)$ and its sign is the same as the effect of ' $c f$ '.

We summarize our findings as follows:

\section{Observation 3 (Coordination)}

1. In both $T 1$ and T2, increasing the inequality ratio $k$ decreases coordination in $C M$, but increases efficient coordination in $C F$.

2. In both $C M$ and $C F$, the presence of a transfer opportunity in T2 increases efficient coordination and reduces inefficient coordination as well as coordination failures.

Observation 3.2 is our central finding, and in the case of CF, it corresponds directly to Observation 2.2 which finds the increased choice of action $X$ in CF-T2 compared with CF-T1. In the case of CM, however, the significant impact of T2 on efficient coordination is not directly implied by our finding on the individual action choice in the preceding section. The positive impact of higher inequality on efficient coordination in CF-T1 (Observation 3.1) is also something that is not evident from the analysis of the individual action choice (Observation 2.4).

\footnotetext{
${ }^{24}$ Note that the number of observations of $(Y, Y)$ is small for any $k$.

${ }^{25}$ The significant effects of the cross terms involving the inequality ratio (i.e., $\mathrm{t} 2 *_{\mathrm{k}} 4$ and $\mathrm{t} 2{ }^{*} \mathrm{k} 6$ ) in the multinomial regression (2) for CM result from small changes in the number of observations of $(Y, X)$ and $(Y, Y)$.

${ }^{26}$ Although the cross term ' $\mathrm{t} 2 * \mathrm{cf}$ ' has a significant positive impact on $(Y, Y)$, the overall effect of ' $t 2$ ' is still negative.
} 


\subsection{What influences the size and likelihood of transfers?}

Figure 6 depicts the average transfer after the realization of each action profile for $\mathrm{CM}$ (left) and $\mathrm{CF}$ (right). In both $\mathrm{CM}$ and $\mathrm{CF}$, the average transfer by the role 1 subjects dominates that by the role 2 subjects. In fact, the average transfer by role 1 (Figure 6) is statistically different from zero in both $\mathrm{CM}$ and $\mathrm{CF}$, implying that the role 1 subjects are on average not own payoff maximizers. The average transfer by role 1 after $(X, X)$ is significantly higher than that after $(X, Y)$ in both $\mathrm{CM}$ and $\mathrm{CF}$ ( $p<0.01$, t-test). The same tendency can be found for role 2 in $\mathrm{CM}$ only $(p<0.01)$.

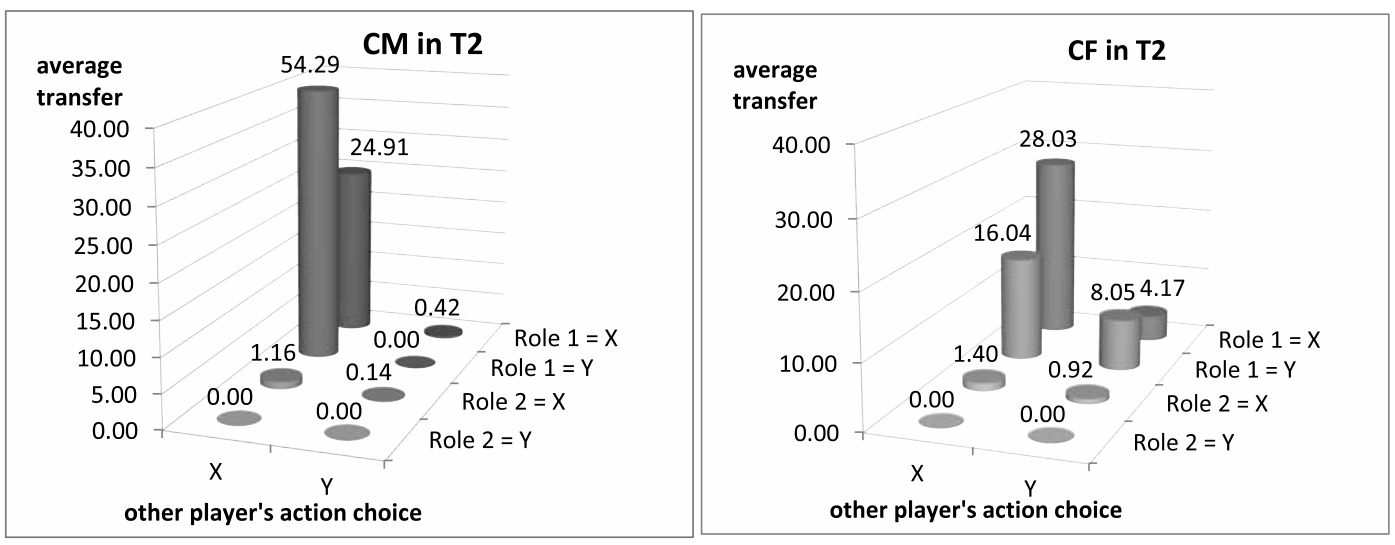

Figure 6: Average absolute transfer: CM (left) and CF (right)

Figure 7 shows the number of subjects who made transfers after the realization of each action profile for CM (left) and CF (right). Those who made positive transfers are predominantly role 1 . It can be seen that a subject tends to make transfers after the choice of $X$ by the other player, and also after the realization of the efficient coordination $(X, X)$.

In order to account for the variation in raw payoff numbers in different inequality games, we also examine the relative transfer, which is defined as the amount of transfer divided by the payoff earned in the game (i.e., $\left.\frac{t_{i}}{u_{i}}\right)$. Figure 8 presents the cumulative distribution of relative transfer by role 1 subjects. The figure indicates that the distribution of relative transfer in CF dominates that in CM. This difference is significant ( $p<0.04$, Kolmogorov-Smirnov test) for role 1, but not for role 2 .

For the analysis of possible determinants of transfer decisions, we restrict attention to the role 1 subjects who have chosen $X$ given that positive transfers are observed almost exclusively in this combination as seen in Figure 7 . Table 6 presents the results of three panel regressions based on data from both CM and CF. Models (1) and (2) are the Tobit regressions of the relative and absolute transfers, 

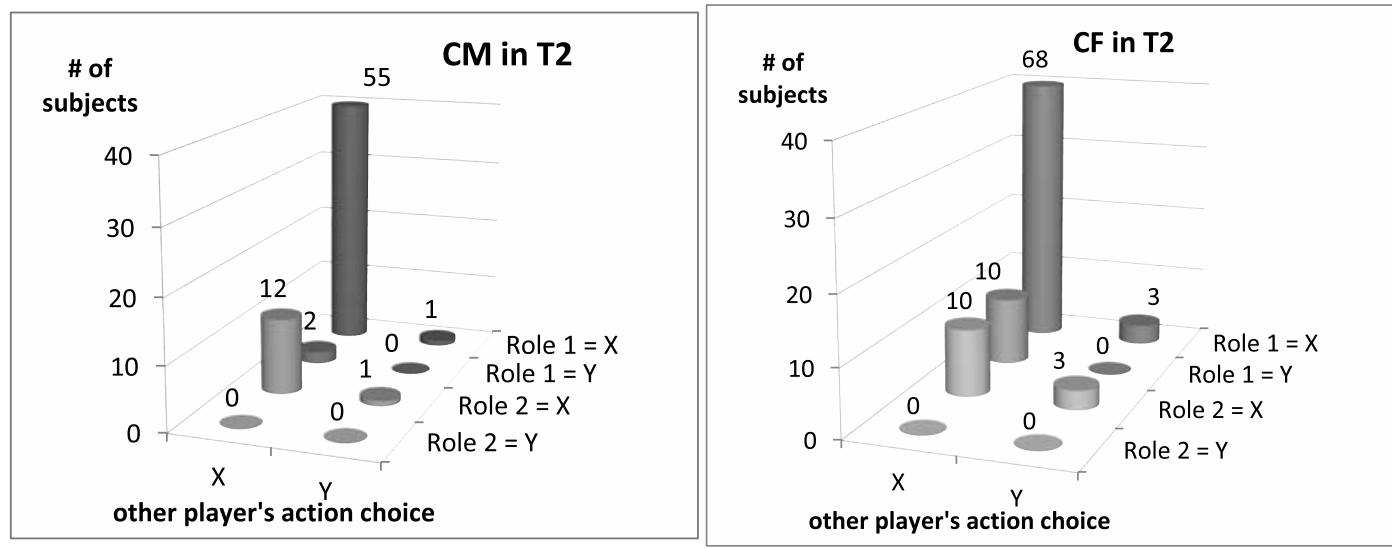

Figure 7: Number of subjects who made positive transfers

respectively, whereas model (3) is the probit regression of the likelihood of positive transfers (i.e., the dependent variable is $\mathbf{1}_{\left\{t_{1}>0\right\}}$ ).

In the Tobit analysis of the relative and absolute transfer in models (1) and (2), the impact of 'other's action' ( $=1$ if role 2 chooses $Y$ ) is negative and significant in each case. The cross term between 'other's action' and ' $c f$ ' is significant in neither model (1) nor model (2). Thus, the role 1 subjects who have chosen $X$ increase their absolute and relative transfer in response to role 2's choice of $X$ in both $\mathrm{CM}$ and $\mathrm{CF}$. The payoff structure ' $c f^{\prime}$ ' has a significant positive effect in both models (1) and (2), and the cross term 'cf $*$ other' $s$ action' is insignificant. In other words, role 1 tends to make a larger transfer in CF than in CM, and this tendency is not affected by role 2's action choice. Role 2's choice of $X$ and CF both have significantly positive impacts on the likelihood of transfer as seen in model (3). Turning now to the inequality ratios ' $\mathrm{k}_{4}$ ' and ' $\mathrm{k}_{6}$ ', we see in both models (1) and (2) that they are positively significant while their cross terms with ' $\mathrm{cf}$ ' are insignificant. It follows that in both CM and CF, role 1 is willing to make a larger transfer as the degree of inequality increases. On the other hand, the likelihood of positive transfers is unaffected by $k$ as seen in model (3).

\section{Observation 4 (Size and frequency of transfer)}

1. The average transfer by role 1 is significantly positive with positive transfer almost exclusively when his own choice is $X$.

2. A positive transfer by role 1 is more likely after the choice of $X$ by role 2, and the absolute and relative transfer is larger in this case.

3. A positive transfer by role 1 is more likely in $C F$, and the absolute and relative transfer is also larger in $C F$. 


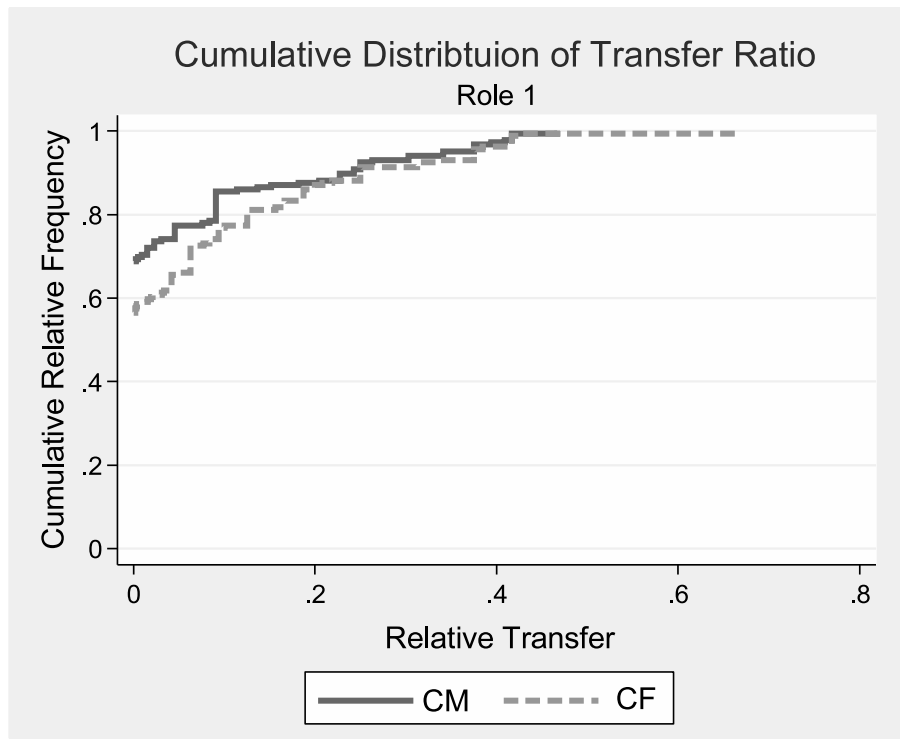

Figure 8: Cumulative distributions of relative transfer by role 1 subjects

4. The inequality ratio $k$ has a positive impact on the (absolute and relative) size of transfer in both CM and CF, but has no impact on the likelihood of a positive transfer.

\subsection{Efficiency and equity with and without a transfer opportunity}

Observations 3.2, 4.1, and 4.2 find that efficient coordination is more likely in the presence of a transfer opportunity and positive transfers do indeed take place. We now turn to the consequence of these observations in terms of the efficiency and equity of the final payoffs.

Our efficiency measure is the total payoff, which simply equals the sum of the two players' payoffs $\left(u_{1}+u_{2}=g_{1}+g_{2}\right)$. The average total payoff in CM is 490.65 for $\mathrm{T} 1$ and 513.92 for $\mathrm{T} 2$. In $\mathrm{CF}$, the average total payoff for $\mathrm{T} 1$ is 301.51 and 340.00 for T2. Statistical significance between T1 and T2 is found in CF ( $p=0.28$ for $\mathrm{CM}$ and 0.03 for $\mathrm{CF}$, by $t$-test). Figure 9 shows the cumulative distribution of the total payoffs in $\mathrm{T} 1$ and $\mathrm{T} 2$. In both $\mathrm{CM}$ and $\mathrm{CF}$, the distribution for $\mathrm{T} 2$ (dashed-line) appears to approximately first-order dominate that for T1 (solid-line). The Kolmogorov-Smirnov test finds a significant difference in distribution between T1 and T2 (dashed-line) in CF (two-sided $p=0.07$ ). The transfer opportunity hence has a more substantial impact on efficiency in CF than in CM. These results are all consistent with our earlier findings that T2 facilitates efficient coordination (Observation 3.2), and has a stronger impact in $\mathrm{CF}$. 


\begin{tabular}{|c|c|c|c|}
\hline Model & $(1)$ & $(2)$ & (3) \\
\hline Dept. var. & relative & absolute & frequency \\
\hline other's action & $\begin{array}{c}-0.27^{* * *} \\
(0.09)\end{array}$ & $\begin{array}{c}-142.89^{* * *} \\
(40.72)\end{array}$ & $\begin{array}{c}-2.47^{* *} \\
(1.21)\end{array}$ \\
\hline $\mathrm{cf}$ & $\begin{array}{c}0.12^{* * *} \\
(0.03)\end{array}$ & $\begin{array}{c}32.16^{* *} \\
(15.17)\end{array}$ & $\begin{array}{c}0.92^{* *} \\
(0.39)\end{array}$ \\
\hline $\mathrm{k}_{4}$ & $\begin{array}{l}0.05^{*} \\
(0.03)\end{array}$ & $\begin{array}{c}38.73^{* * *} \\
(14.12)\end{array}$ & $\begin{array}{c}0.34 \\
(0.37)\end{array}$ \\
\hline $\mathrm{k}_{6}$ & $\begin{array}{c}0.07^{* * *} \\
(0.03)\end{array}$ & $\begin{array}{c}73.15^{* * *} \\
(13.58)\end{array}$ & $\begin{array}{c}0.43 \\
(0.36)\end{array}$ \\
\hline other's action * ${ }^{*}$ & $\begin{array}{c}0.13 \\
(0.09)\end{array}$ & $\begin{array}{c}33.08 \\
(45.33)\end{array}$ & $\begin{array}{l}-0.13 \\
(1.23)\end{array}$ \\
\hline $\mathrm{cf}^{*} \mathrm{k}_{4}$ & $\begin{array}{l}-0.06 \\
(0.04)\end{array}$ & $\begin{array}{l}-12.61 \\
(20.57)\end{array}$ & $\begin{array}{c}0.14 \\
(0.55)\end{array}$ \\
\hline $\mathrm{cf}^{*} \mathrm{k}_{6}$ & $\begin{array}{l}-0.06 \\
(0.04)\end{array}$ & $\begin{array}{l}-21.27 \\
(19.24)\end{array}$ & $\begin{array}{c}0.49 \\
(0.54)\end{array}$ \\
\hline $1 /$ round & $\begin{array}{c}0.04 \\
(0.03)\end{array}$ & $\begin{array}{l}24.61^{*} \\
(13.72)\end{array}$ & $\begin{array}{c}0.98 * * \\
(0.40)\end{array}$ \\
\hline constant & $\begin{array}{c}-0.13^{* * *} \\
(0.04) \\
\end{array}$ & $\begin{array}{c}-82.57^{* * *} \\
(16.97) \\
\end{array}$ & $\begin{array}{c}-1.61^{* * *} \\
(0.43) \\
\end{array}$ \\
\hline \# & 3335 & 335 & 335 \\
\hline Log-likelihood & -13.61 & -788.56 & -153.66 \\
\hline
\end{tabular}

Table 6: Random effect Tobit and probit regressions of transfer size and frequency

Further scrutiny of the subjects' payoffs reveals interesting facts. Figure 10 depicts the average final payoffs $\left(g_{i}\right)$ in $\mathrm{T} 1$ and $\mathrm{T} 2$ for role 1 (dark) and role 2 (light). While role 2's payoff in T2 is significantly higher than that in T1 in both $\mathrm{CM}$ and $\mathrm{CF}$ ( $p<0.01$ in both CM and CF by a $t$-test and a Mann-Whitney test), there is no such difference in role 1's payoffs (by either test).

Table 7 presents the Tobit regression of the final payoff. As seen, there is a sharp contrast between role 1 (left) and role 2 (right): For role 1, neither ' $t 2$ ' nor any cross term involving ' $t 2$ ' is significant. For role 2, on the other hand, 't2' is significantly positive in $\mathrm{CF}$, and the cross terms involving ' $\mathrm{t} 2$ ' tend to be significantly positive. In particular, the cross term ' $\mathrm{t} 2 * \mathrm{k}_{6}$ ' is strongly positively significant in both CM and $\mathrm{CF}$. The positive impact of ' $\mathrm{t} 2$ ' on role 2's payoff is consistent with the significantly positive transfer by role 1 in $\mathrm{T} 2$ as seen earlier. On the other hand, the insignificance of 't2' on role 1's payoff, coupled with Observations 3.2 and 4.2, implies that role 1 transfers away any payoff gain from more efficient coordination achieved in T2.

We now turn to the question of equity, which is measured by the ratio of the 

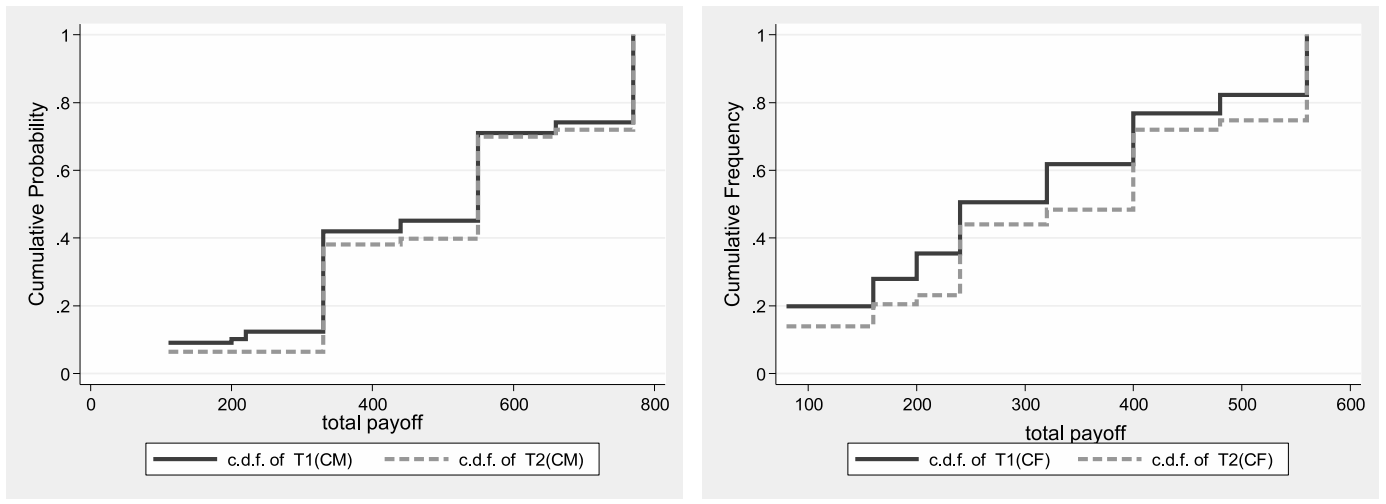

Figure 9: Cumulative distributions of total payoffs in T1 and T2: CM (left) and CF (right)
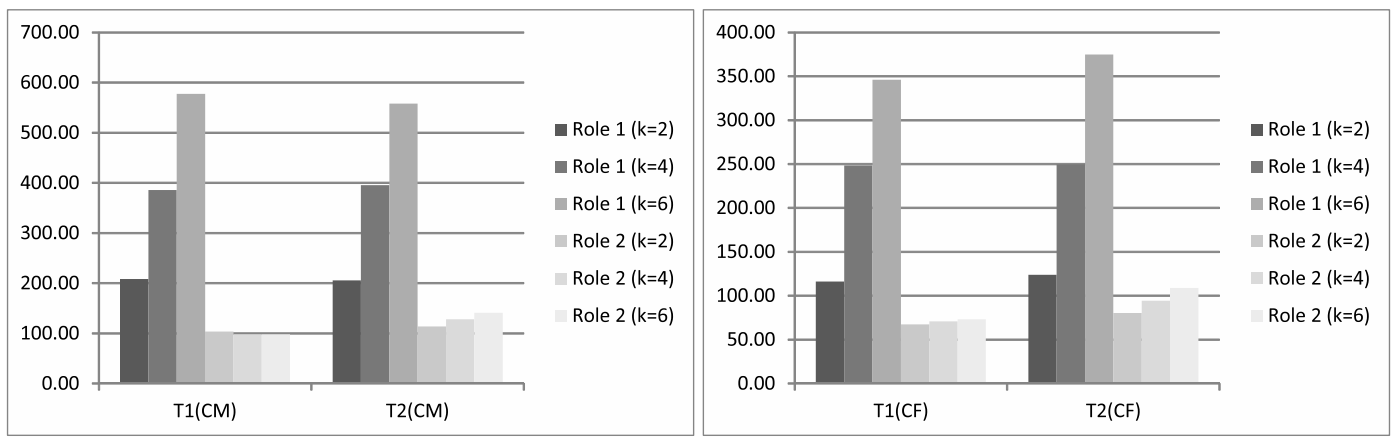

Figure 10: Final payoffs $g_{i}$ in CM (left) and CF (right)

final payoffs:

$$
\frac{g_{1}}{g_{2}}=\frac{\text { role } 1 \text { 's final payoff }}{\text { role } 2 \text { 's final payoff }}
$$

Figure 11 shows the average of the payoff ratio for T1 (dark) and T2 (light). For each $k$, we can see that the average ratio is lower for T2 in both CM and CF. This indicates that the presence of a transfer opportunity contributes to reducing inequality between the two players. The hypothesis that there is no difference in the average payoff ratio between $\mathrm{T} 1$ and $\mathrm{T} 2$ is rejected by $t$-test for all $k$ in $\mathrm{CM}$ with $p<0.05$, and for $k=2$ and $k=4$ in CF with $p<0.01 .^{27}$

Table 8 reports the Tobit regressions of the payoff ratio for each inequality ratio separately. The improvement in equity in $\mathrm{T} 2$ is observed in both $\mathrm{CM}$ and $\mathrm{CF} .{ }^{28}$

\footnotetext{
${ }^{27}$ The reduction in the payoff ratio in $\mathrm{T} 2$ is also confirmed by the Kolmogorov-Smirnov test $(p<0.03$ for $\mathrm{CM}$ and $p<0.01$ for $\mathrm{CF})$.

${ }^{28}$ This is reflected by the significant negative impact of ' $t 2$ ' in all three models, together with the cross term between 'cf' and 't2' being either significantly negative (model (1)) or insignificant (model (2) and (3)). By design, the payoff ratio tends to be lower in CF than in CM.
} 


\begin{tabular}{|c|c|c|c|c|}
\hline \multirow[b]{2}{*}{ Model } & \multicolumn{2}{|c|}{ Role 1} & \multicolumn{2}{|c|}{ Role 2} \\
\hline & $\begin{array}{l}\mathrm{CM} \\
(1)\end{array}$ & $\begin{array}{l}\mathrm{CF} \\
(2)\end{array}$ & $\begin{array}{c}\text { CM } \\
(3)\end{array}$ & $\begin{array}{l}\text { CF } \\
(4)\end{array}$ \\
\hline $\mathrm{t} 2$ & $\begin{array}{c}-3.12 \\
(22.31)\end{array}$ & $\begin{array}{c}7.69 \\
(20.45)\end{array}$ & $\begin{array}{l}10.08 \\
(7.82)\end{array}$ & $\begin{array}{c}12.56^{* *} \\
(6.04)\end{array}$ \\
\hline $\mathrm{k}_{4}$ & $\begin{array}{c}174.39^{* * *} \\
(23.22)\end{array}$ & $\begin{array}{c}132.13^{* * *} \\
(20.53)\end{array}$ & $\begin{array}{l}-5.61 \\
(8.14)\end{array}$ & $\begin{array}{c}3.07 \\
(6.07)\end{array}$ \\
\hline $\mathrm{k}_{6}$ & $\begin{array}{c}367.64^{* * *} \\
(22.50)\end{array}$ & $\begin{array}{c}230.09^{* * *} \\
(20.32)\end{array}$ & $\begin{array}{l}-5.63 \\
(7.88)\end{array}$ & $\begin{array}{c}5.86 \\
(6.00)\end{array}$ \\
\hline $\mathrm{t} 2^{*} \mathrm{k}_{4}$ & $\begin{array}{c}12.18 \\
(31.56)\end{array}$ & $\begin{array}{c}-6.03 \\
(29.98)\end{array}$ & $\begin{array}{c}19.68^{*} \\
(11.06)\end{array}$ & $\begin{array}{r}11.44 \\
(8.87)\end{array}$ \\
\hline $\mathrm{t} 2^{*} \mathrm{k}_{6}$ & $\begin{array}{l}-15.65 \\
(31.58)\end{array}$ & $\begin{array}{c}21.00 \\
(28.52)\end{array}$ & $\begin{array}{c}32.65^{* * *} \\
(11.07)\end{array}$ & $\begin{array}{c}23.03^{* * *} \\
(8.42)\end{array}$ \\
\hline $1 /$ round & $\begin{array}{c}12.01 \\
(25.48)\end{array}$ & $\begin{array}{c}0.71 \\
(21.87)\end{array}$ & $\begin{array}{l}-0.12 \\
(8.93)\end{array}$ & $\begin{array}{c}1.75 \\
(6.54)\end{array}$ \\
\hline constant & $\begin{array}{c}204.77^{* * *} \\
(18.08) \\
\end{array}$ & $\begin{array}{c}115.86^{* * *} \\
(16.42) \\
\end{array}$ & $\begin{array}{c}103.91^{* * *} \\
(6.35)\end{array}$ & $\begin{array}{c}66.93^{* * *} \\
(4.97) \\
\end{array}$ \\
\hline \# of obs. & 372 & 372 & 372 & 372 \\
\hline Log-likelihood & -2333.37 & -2283.6033 & -1944.21 & -1839.3891 \\
\hline
\end{tabular}

Table 7: Random effects Tobit regressions of final payoffs

These findings are consistent with our observation from Figure 11.

Observation 5 (Efficiency and equity)

1. T2 increases efficiency in CF, and the increase in efficiency is almost entirely brought about by the increase in role 2's payoff.

2. In both $C M$ and $C F$, T2 increases equity as measured by the final payoff ratio.

\section{Discussion}

One important question concerns what motivates positive transfer in the redistribution stage. Among the social preferences discussed earlier, IEA is found to be consistent with the subjects' choice in T0, but is irrelevant in the redistribution stage since the game is constant-sum then. On the other hand, IQA is not supported by the subjects' choice in T0, but can be a source of positive transfer by the role 1 subjects. Another possible source of positive transfer is reciprocity, which in this case is the response by role 1 to role 2 's choice of $X$ that contributes primarily to increasing role 1's payoff. ${ }^{29}$ The strength of reciprocity can depend on (i) the

\footnotetext{
${ }^{29}$ Reciprocity is a response by player $i$ based on his interpretation of another player $j$ 's intention when $j$ 's behavior affects $i$ 's payoff. Reciprocity is positive if $i$ rewards $j$ for $j$ 's action that is
} 

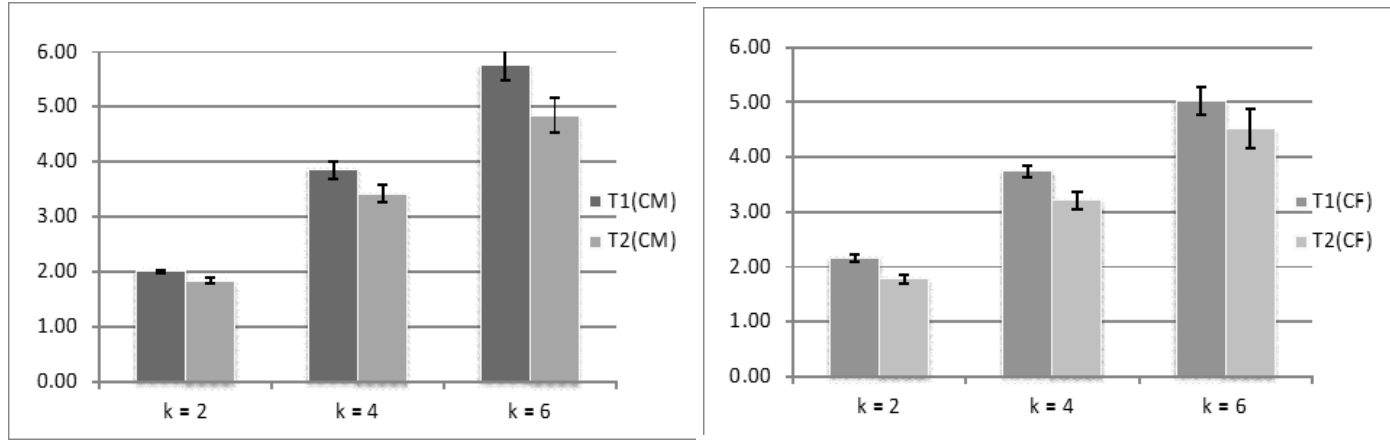

Figure 11: Final payoff ratios $g_{1} / g_{2}$ in CM (left) and CF (right)

amount of sacrifice that role 2 makes by choosing $X$, and (ii) the size of the benefit role 2 provides to role 1 by choosing $X$.

The following considerations provide us some hint as to which one of IQA and reciprocity motivates positive transfer by role 1 . First, in the case of IQA, the transfer would be driven only by the realized payoff difference between two roles at the end of stage 1 in both $\mathrm{CM}$ and $\mathrm{CF} .{ }^{30}$ Reciprocity based on the benefit measure also fails to distinguish between $\mathrm{CM}$ and $\mathrm{CF}$ : In both games, role 2's choice of $X$ unambiguously benefits role 1 . On the other hand, reciprocity based on the sacrifice measure has different implications for $\mathrm{CM}$ and $\mathrm{CF}$. In $\mathrm{CM}$, role 2 prefers $(X, X)$ to $(Y, Y)$, but in $\mathrm{CF}$, role 2 prefers $(Y, Y)$ to $(X, X)$. According to reciprocity based on the sacrifice measure, hence, more transfer is expected in CF than in CM. Our finding (Observation 4.3) supports the latter reasoning.

Examining the effect of the inequality ratio $k$ also provides some hint. Clearly, a larger $k$ would have a positive impact on the size of transfer based on IQA or reciprocity with the benefit measure. This is indeed what we find in Observation 4.4. On the other hand, we also find that the likelihood of positive transfer is unaffected by $k$, which can be considered evidence against IQA or reciprocity based on the benefit measure. ${ }^{31}$ Although the above considerations do not distinguish between IQA and reciprocity based on the benefit measure, rejection of IQA by our findings from T0 leads us to the following conjecture:

Conjecture 1 Reciprocity based on the sacrifice measure plays as the primary motive behind positive transfers in T2, whereas reciprocity based on the benefit measure plays the secondary role.

interpreted as intending to benefit $i$, and is negative if $i$ punishes $j$ for $j$ 's action that is interpreted as intending to harm $i$. Our experimental design allows us to observe only positive reciprocity.

${ }^{30}$ If anything, the payoff difference $u_{1}(X, X)-u_{2}(X, X)$ is larger in CM than in CF for each $k$, so that more transfer may be expected in CM based on IQA or reciprocity based on the benefit measure.

${ }^{31}$ The insignificance of the cross term between ' $c f$ ' and ' $k_{4}$ ' or ' $k_{6}$ ' indicates that the larger transfer in $\mathrm{CF}$ is not driven by the inequality ratio $k$. 


\begin{tabular}{lccc}
\hline Model & $(1)$ & $(2)$ & $(3)$ \\
& $k=2$ & $k=4$ & $k=6$ \\
t2 & $-0.17^{* *}$ & $-0.44^{* *}$ & $-0.90^{* *}$ \\
& $(0.08)$ & $(0.20)$ & $(0.41)$ \\
$\mathrm{cf}$ & $0.16^{* *}$ & -0.12 & $-0.69^{*}$ \\
& $(0.08)$ & $(0.20)$ & $(0.42)$ \\
$\mathrm{cf} * \mathrm{t} 2$ & $-0.21^{*}$ & -0.08 & 0.38 \\
& $(0.12)$ & $(0.29)$ & $(0.58)$ \\
$1 /$ round & -0.03 & 0.03 & 0.34 \\
& $(0.12)$ & $(0.25)$ & $(0.58)$ \\
constant & $2.01^{* * *}$ & $3.85^{* * *}$ & $5.62^{* * *}$ \\
& $(0.07)$ & $(0.20)$ & $(0.38)$ \\
\hline \hline \# of obs. & 248 & 248 & 248 \\
Log-likelihood & -162.85 & -388.26 & -562.18 \\
\hline *,**and ***: significant at $10 \%, 5 \%$ and $1 \%$, respectively \\
Standard errors are in parentheses.
\end{tabular}

Table 8: Tobit regressions of payoff ratio $g_{1} / g_{2}$

The second question concerns whether the subjects' choice of $X$ instead of $Y$ in CF (Observations 2.2 and 2.4) can be rationalized ex post in T2. To answer this question, suppose that the subjects take as given the average transfer from role 1 to role 2 in T2 contingent on each action profile. Figure 12 incorporates the average transfer from role 1 to role 2 in T2 into their payoffs in CF with the number of observations of each action in the corresponding treatment indicated in the parentheses. It can be seen that $X$ becomes a more attractive choice for role 2 than in the original game. In fact, $X$ is a dominant action for role 2 when $k=6$, and $(X, X)$ is a payoff dominant equilibrium as in CM when $k=4$. Furthermore, if role 2 expects that role 1's action choice is given by its empirical frequency, $X$ is his uniquely optimal action for every $k$. For role 1 , on the other hand, $X$ cannot be a dominant action for any $k$ by construction. Again, however, if role 1 expects that role 2's action choice is given by its empirical frequency, $X$ is the uniquely optimal action for role 1 for every $k$.

\begin{tabular}{|c|c|c||c|c|c||c|c|c|}
\hline & $\mathrm{X}(51)$ & $\mathrm{Y}(11)$ & & $\mathrm{X}(52)$ & $\mathrm{Y}(10)$ & & $\mathrm{X}(52)$ & $\mathrm{Y}(10)$ \\
\hline$X(48)$ & $149.1,90.9$ & $53.3,26.7$ & $X(53)$ & $292.1,107.9$ & 60,20 & $X(55)$ & $437.6,122.4$ & $59.7,20.3$ \\
$Y(14)$ & $95.4,64.6$ & 100,100 & $Y(9)$ & $244.3,75.8$ & 100,100 & $Y(7)$ & 376,104 & 100,100 \\
\hline
\end{tabular}

$$
k=2 \quad k=4 \quad k=6
$$

Figure 12: Payoff matrices incorporating the average transfer from role 1 to role 2 in $\mathrm{T} 2\left(=\left(u_{1}-\bar{t}_{1}, u_{2}+\bar{t}_{1}\right)\right)$ 


\section{Conclusion}

We study the play of a $2 \times 2$ coordination game which gives player 1 a large advantage over player 2, and examine the effect of adding the ex post redistribution stage where each player may voluntarily transfer their payoff to the other player. We find that the presence of the redistribution stage induces positive transfer from the role 1 subjects to the role 2 subjects, and more frequent coordination on the efficient action profile. These tendencies are stronger when the two players have conflicting preferences over the two equilibria of the coordination game than when they have common interests.

While the subjects' choices in the non-strategic situation are mostly consistent with own profit maximization, their behavior in the strategic situation deviates significantly from it. Through the analysis of the size and frequency of transfer, we conclude that the positive transfer is most likely motivated by reciprocity by the role 1 players and anticipation of it by the role 2 players. We find that this interaction results in the higher levels of efficiency and equity.

One interesting extension of the present work is an experiment that involves elicitation of beliefs from the subjects before the play of the game. In particular, it would be interesting to find out their beliefs about which action they expect from the other player, and how much transfer they expect from the other player after the realization of a particular action profile. Such study would provide us with more insight into the thinking of subjects in the face of inequality.

Our finding suggests that the opportunity to voluntarily redistribute wealth can partially mitigate inequality. In our experiments, inequality is given by the experimenter and not a consequence of the subjects' effort. It would be interesting to see if behavior is different in the setting where inequality is "acquired" by the subjects as a result of their real effort in some preceding task.

\section{References}

M. Agranov and T. R. Palfrey. Equilibrium tax rates and income redistribution: A laboratory study. Journal of Public Economics, 130:45-58, 2015.

L. R. Anderson, J. M. Mellor, and J. Milyo. Inequality and public good provision: An experimental analysis. Journal of Socio-Economics, 37:1010-1028, 2008.

L. Belafoutas, M. G. Kocher, L. Putterman, and M. Sutter. Equality, equity and incentives: An experiment. European Economic Review, 60:32-51, 2013.

E. Buckley and R. Croson. The poor give more: Income and wealth heterogeneity in the voluntary provision of linear public goods. Journal of Public Economics, 90(5):935-955, 2006. 
C. F. Camerer. Behavioral Game Theory: Experiments in Strategic Interaction. Princeton University Press, 2003.

K. S. Chan, S. Mestelman, R. Moir, and R. A. Muller. The voluntary provision of public goods under varying income distributions. Canadian Journal of Economics, 29(1):54-69, 1996.

K. S. Chan, S. Mestelman, R. Moir, and R. A. Muller. Heterogeneity, equity and voluntary contributions toward the provision of a public good. Experimental Economics, 2:5-30, 1999.

R. Cooper, D. V. DeJong, R. Forsythe, and T. W. Ross. Communication in coordination games. Quarterly Journal of Economics, 107(2):739-771, 1992.

R. W. Cooper, D. V. DeJong, R. Forsythe, and T. W. Ross. Selection criteria in coordination games: Some experimental results. American Economic Review, 80(1): 218-233, 1990. ISSN 00028282. URL http://www.jstor.org/stable/2006744.

V. P. Crawford, U. Gneezy, and Y. Rottenstreich. The power of focal points is limited: Even minute payoff asymmetry may yield large coordination failures. American Economic Review, 98(4):1443-1458, 2008.

R. Durante, L. Putterman, and J. van de Weele. Preferences for redistribution and perception of fairness: An experimental study. Journal of the European Economic Association, 12(4):1059-1086, 2014.

N. Erkal, L. Gangadharan, and N. Nikiforakis. Relative earnings and giving in a real-effort experiment. American Economic Review, 101:3330-3348, 2011.

U. Fischbacher. z-Tree: Zurich toolbox for ready-made economic experiments. Experimental Economics, 10(2):171-178, 2007.

J. K. Goeree and C. A. Holt. An experimental study of costly coordination. Games and Economic Behavior, 51:349-364, 2005.

B. Greiner, A. Ockenfels, and P. Werner. The dynamic interplay of inequality and trust? An experimental study. Journal of Economic Behavior $\&$ Organization, 81(2):355-365, 2012.

S. P. Hargreaves Heap, J. H. W. Tan, and D. J. Zizzo. Trust, inequality and the market. Theory and Decision, 74:311-333, 2013.

A. Hofmeyr, J. Burns, and M. Visser. Income inequality, reciprocity and public good provision: An experimental analysis. South African Journal of Economics, 75:508-520, 2007.

M. Krawczyk. A glimpse through the veil of ignorance: Equality of opportunity and support for redistribution. Journal of Public Economics, 94(1-2):131-141, 2010. 
J. Maurice, A. Rouaix, and M. Willinger. Income redistribution and public good provision: An experiment. International Economic Review, 54(3):957-975, 2013.

F. Ohtake, Y. Kinari, N. Mizutani, and T. Mori. Income, giving, and egalitarianism: A real-effort experiment in japan. Journal of Behavioral Economics and Finance, 6:81-84, 2013. (in Japanese).

R. J. Oxoby and J. Spraggon. A clear and present minority: Heterogeneity in the source of endowments and the provision of public goods. Economic Inquiry, 51 (4):2071-2082, 2013.

E. E. Rutström and M. B. Williams. Entitlements and fairness: an experimental study of distributive preferences. Journal of Economic Behavior and Organization, $43(1): 75-89,2000$.

P. G. Straub. Risk dominance and coordination failures in static games. Quarterly Review of Economics and Finance, 35(4):339-363, 1995.

A. Tavoni, A. Dannenberg, G. Kallis, and A. Lösche. Inequality, communication, and the avoidance of disastrous climate change in a public goods game. Proceedings of the National Academy of Science, 108(29):11825-11829, 2011.

J.-R. Tyran and R. Sausgruber. A little fairness may induce a lot of redistribution in democracy. European Economic Review, 50(2):469-485, 2006.

N. Uler. Public goods provision, inequality and taxes. Experimental Economics, 14: 287-306, 2011.

J. B. Van Huyck, R. C. Battalio, and R. O. Beil. Tacit coordination games, strategic uncertainty, and coordination failure. American Economic Review, 80(1):234-248, March 1990. 


\section{Appendix}

\section{Instruction}

\section{For those who will participate in the experiment}

The experiment we are about to conduct will be used as academic material to analyze your choice behavior. You will be asked to make choices according to the following rules. Through those choices, you will earn points. All the points you earn will be converted to cash at a rate of 1.3 yen per point, which will be paid to you at the end of the experiment. All instructions for making the choices will be shown on the computer screen in front of you. The experiment is divided into four parts.

\section{Part 1}

Explanation of the experiment

Once the experiment begins, the computer will first randomly choose half of the participants as selectors. In Part 1, only these selectors will make choices. There is nothing for those who were not chosen as a selector to do in Part 1 of the experiment; if you were not chosen, please wait until Part 2 begins.

Those who were chosen as selectors will be asked to make six rounds of selections, as explained below. First, a selector will be paired with an individual who was not chosen as a selector. A selector will not be paired with another selector. Likewise, individuals who were not chosen as selectors will not be paired together. The individual you are going to be paired with will be randomly determined by the computer for each round of selection.

The selector will choose one of four options, A, B, C, and D. Based on the choice made by the selector, points are determined for you (the selector) and your counterpart (an individual who was not chosen as a selector).

\begin{tabular}{|c|cc|}
\hline Options & Your Points & $\begin{array}{c}\text { Points for Your } \\
\text { Counterpart }\end{array}$ \\
\hline A & Numerical value $a$ & Numerical value $b$ \\
\hline B & Numerical value $c$ & Numerical value $d$ \\
\hline C & Numerical value $e$ & Numerical value $f$ \\
\hline D & Numerical value $g$ & Numerical value $h$ \\
\hline
\end{tabular}

The table above shows the four options and their corresponding points for you and your counterpart. During the experiment, $a$ through $h$ will have specific numerical values and will change in each round. 
For example, when, as the selector, you choose B, you will the receive points shown for the numerical value $c$, while your counterpart (an individual who was not chosen as a selector) will receive the points shown for numerical value $d$.

\section{Formulae to Derive Points}

Points for you (the selector) and your counterpart (an individual who was not chosen as a selector) are calculated according to the following formulae.

Your points $=100 \times \mathrm{M} \times \mathrm{N}+60 \times(1-\mathrm{M})+s \times(1-\mathrm{N})$

Points for your counterpart $=100 \times \mathrm{M} \times \mathrm{N}+60 \times(1-\mathrm{N})+t \times(1-\mathrm{M})$

$\mathrm{M}$ and $\mathrm{N}$ will each have a value of either 0 or 1 ; their combinations correspond to the options as follows:

Option $\mathrm{A}$ in the table above: $\mathrm{M}=0$ and $\mathrm{N}=0$

Option B in the table above: $\mathrm{M}=0$ and $\mathrm{N}=1$

Option $\mathrm{C}$ in the table above: $\mathrm{M}=1$ and $\mathrm{N}=0$

Option D in the table above: $\mathrm{M}=1$ and $\mathrm{N}=1$

The values of $s$ and $t$ are different and change in each round.

\section{Numerical Value Example 1}

Let us say the value of $s$ is 30 and the value of $t$ is 100. In this case, points will be given as follows:

When you choose Option $\mathrm{A}(\mathrm{M}=0, \mathrm{~N}=0)$,

Your points $=100 \times 0 \times 0+60 \times(1-0)+30 \times(1-0)=90$

Points for your counterpart $=100 \times 0 \times 0+60 \times(1-0)+100 \times(1-0)=160$.

When you choose Option B $(\mathrm{M}=0, \mathrm{~N}=1)$,

Your points $=100 \times 0 \times 1+60 \times(1-0)+30 \times(1-1)=60$

Points for your counterpart $=100 \times 0 \times 1+60 \times(1-1)+100 \times(1-0)=100$.

When you choose Option $\mathrm{C}(\mathrm{M}=1, \mathrm{~N}=0)$,

Your points $=100 \times 1 \times 0+60 \times(1-1)+30 \times(1-0)=30$

Points for your counterpart $=100 \times 1 \times 0+60 \times(1-0)+100 \times(1-1)=60$.

When you choose Option D $(\mathrm{M}=1, \mathrm{~N}=1)$,

Your points $=100 \times 1 \times 1+60 \times(1-1)+30 \times(1-1)=100$

Points for your counterpart $=100 \times 1 \times 1+60 \times(1-1)+100 \times(1-1)=100$.

In other words, the point table in this example will be as follows. 


\begin{tabular}{|c|cc|}
\hline Options & Your Points & $\begin{array}{c}\text { Points for Your } \\
\text { Counterpart }\end{array}$ \\
\hline A & 90 & 160 \\
\hline B & 60 & 100 \\
\hline C & 30 & 60 \\
\hline D & 100 & 100 \\
\hline
\end{tabular}

Numerical Value Example 2

Let's say the value of $s$ is 140 and the value of $t$ is 55 . In this case, the points will be as follows:

When you choose Option A $(\mathrm{M}=0, \mathrm{~N}=0)$,

Your points $=100 \times 0 \times 0+60 \times(1-0)+140 \times(1-0)=200$

Points for your counterpart $=100 \times 0 \times 0+60 \times(1-0)+55 \times(1-0)=115$.

When you choose Option B $(\mathrm{M}=0, \mathrm{~N}=1)$,

Your points $=100 \times 0 \times 1+60 \times(1-0)+140 \times(1-1)=60$

Points for your counterpart $=100 \times 0 \times 1+60 \times(1-1)+55 \times(1-0)=55$.

When you choose Option $\mathrm{C}(\mathrm{M}=1, \mathrm{~N}=0)$,

Your points $=100 \times 1 \times 0+60 \times(1-1)+140 \times(1-0)=140$

Points for your counterpart $=100 \times 1 \times 0+60 \times(1-0)+55 \times(1-1)=60$.

When you choose Option $\mathrm{D}(\mathrm{M}=1, \mathrm{~N}=1)$,

Your points $=100 \times 1 \times 1+60 \times(1-1)+140 \times(1-1)=100$

Points for your counterpart $=100 \times 1 \times 1+60 \times(1-1)+55 \times(1-1)=100$.

The point table in this example will be as follows.

\begin{tabular}{|c|cc|}
\hline Options & Your Points & $\begin{array}{c}\text { Points for Your } \\
\text { Counterpart }\end{array}$ \\
\hline A & 200 & 115 \\
\hline B & 60 & 55 \\
\hline C & 140 & 60 \\
\hline D & 100 & 100 \\
\hline
\end{tabular}


Explanation of the Computer Screens and Tasks to Be Performed During the Experiment Screen for the selector

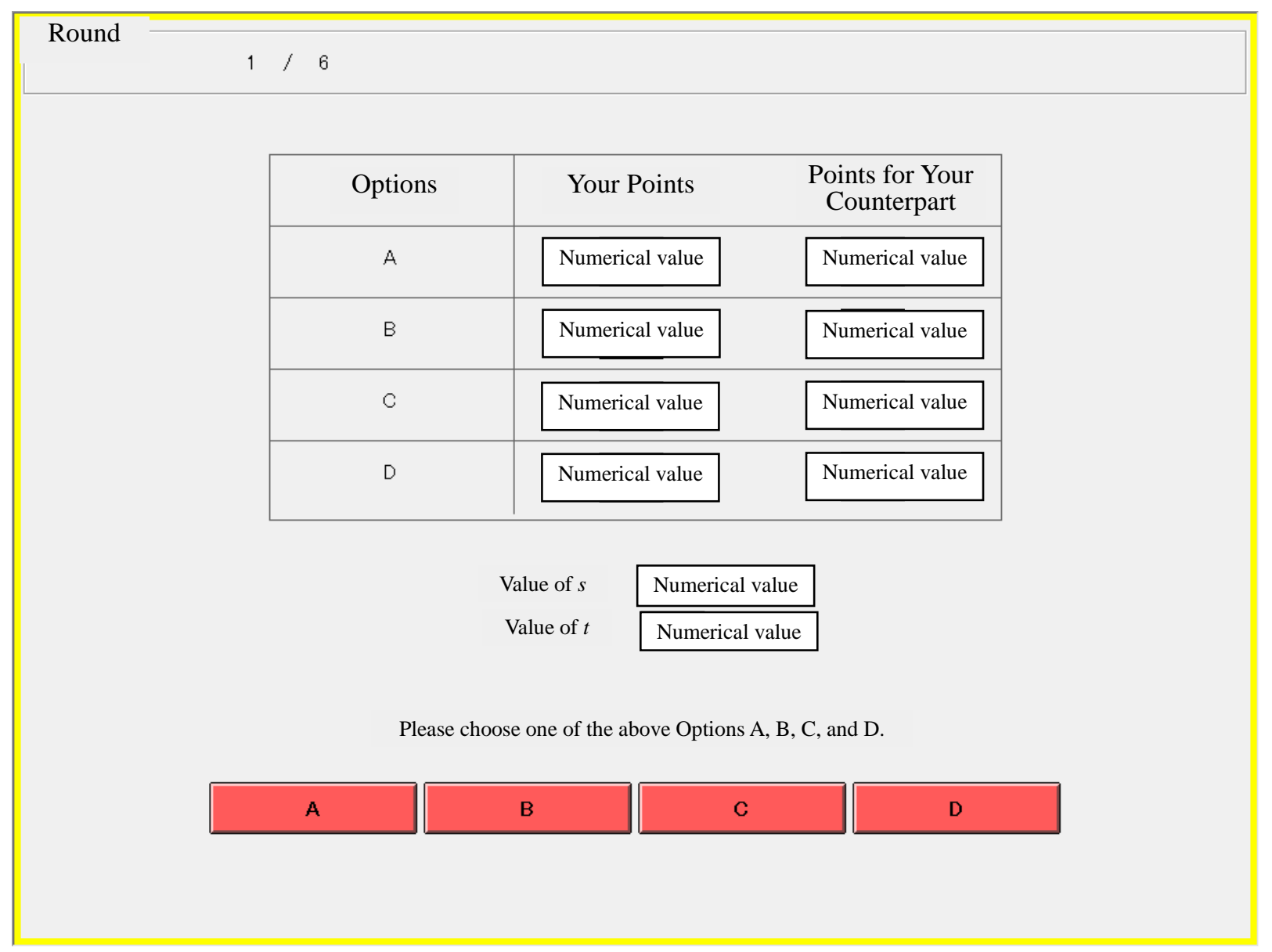

The above screen will be displayed for those who are chosen as selectors. The selection round is shown at the top of the screen. In the above example, the round is the first of six.

Four options and their corresponding points for you and your counterpart are shown in the center of the screen. These points will change each round. Below that, you will find the values of $s$ and $t$ that are used in the formulae to derive the points. Below that are the selection buttons.

First, please choose one option from A, B, C, and D and write it under "Your Choice" on the record sheet. Please also write why you made that choice in the "Reasons for Your Choice" section.

When you've finished writing, please click on the button for the option you wrote in "Your Choice."

Once all selectors click on an option button, the next round will begin. This completes one round of selection. This is repeated six times. 
Screen for those who were not chosen as a selector

You were not chosen as a selector.

You will not make choices during Part 1 of the experiment.

Please wait until Part 2 begins.

The above screen will be displayed for those who were not chosen as selectors. Please wait until Part 2 begins, as you will not make choices in Part 1 of the experiment.

You will now have three minutes to review the details of the experiment. If you have a question, please raise your hand quietly and the experimenter will answer you one-to-one. Please note that you are not allowed to communicate with the other participants. 


\section{Part 2}

Explanation of the Experiment Details

Everyone will be asked to make choices starting in Part 2. You will make six rounds of selections as explained below. First, you will be paired with another participant. The individual you are paired with will be randomly chosen by the computer for each round of selection.

You will choose one of two options, $\mathrm{X}$ and $\mathrm{Y}$. The points for you and your counterpart will be determined on the basis of the choices you and your counterpart make.

\begin{tabular}{|c|c|c|c|}
\hline \multirow{3}{*}{\multicolumn{2}{|c|}{$\mathrm{X}$}} & \multicolumn{2}{|c|}{ Choice of Your Counterpart } \\
\hline & & $\mathrm{X}$ & $\mathrm{Y}$ \\
\hline & & $\begin{array}{l}\text { Numerical value } a \text {, } \\
\text { Numerical value } b\end{array}$ & $\begin{array}{l}\text { Numerical value } c \text {, } \\
\text { Numerical value } d\end{array}$ \\
\hline Your Choice & $\mathrm{Y}$ & $\begin{array}{l}\text { Numerical value } e \text {, } \\
\text { Numerical value } b\end{array}$ & $\begin{array}{l}\text { Numerical value } g \text {, } \\
\text { Numerical value } h\end{array}$ \\
\hline
\end{tabular}

The $\mathrm{X}$ and $\mathrm{Y}$ on the left side represent your choice and the $\mathrm{X}$ and $\mathrm{Y}$ on the top represent the choice of your counterpart. The two numerical values in each cell represent the points for you and your counterpart corresponding to each combination of choices. The value on the left in each cell is your points and the value on the right is the points for your counterpart. During the experiment, numerical points $a$ through $h$ will have specific values and will change in each round.

For example, when your choice is $\mathrm{X}$ and the choice of your counterpart is $\mathrm{Y}$, you will receive the points shown by numerical value $c$ and your counterpart will receive the points shown by numerical value $d$.

\section{Formulae to Derive Points}

Your choices are $0(\mathrm{X})$ and $1(\mathrm{Y})$. Points for you and your counterpart are calculated according to the following formulae.

$$
\begin{aligned}
& \text { Your points }=100 \times(\text { your choice }) \times(\text { choice of your counterpart }) \\
& +60 \times(1-\text { your choice })+s \times(1-\text { choice of your counterpart }) \\
& \text { Points for your counterpart }=100 \times(\text { your choice }) \times(\text { choice of your counterpart }) \\
& +60 \times(1-\text { choice of your counterpart })+t \times(1-\text { your choice })
\end{aligned}
$$

The values of $s$ and $t$ are different and change in each round. 


\section{Numerical Value Example 1}

Let us say the value of $s$ is 30 and the value of $t$ is 100 . In this case, the points will be as follows:

When you choose $0(\mathrm{X})$ and your counterpart chooses $0(\mathrm{X})$,

Your points $=100 \times 0 \times 0+60 \times(1-0)+30 \times(1-0)=90$

Points for your counterpart $=100 \times 0 \times 0+60 \times(1-0)+100 \times(1-0)=160$

When you choose $0(\mathrm{X})$ and your counterpart chooses $1(\mathrm{Y})$,

Your points $=100 \times 0 \times 1+60 \times(1-0)+30 \times(1-1)=60$

Points for your counterpart $=100 \times 0 \times 1+60 \times(1-1)+100 \times(1-0)=100$

When you choose $1(\mathrm{Y})$ and your counterpart chooses $0(\mathrm{X})$,

Your points $=100 \times 1 \times 0+60 \times(1-1)+30 \times(1-0)=30$

Points for your counterpart $=100 \times 1 \times 0+60 \times(1-0)+100 \times(1-1)=60$

When you choose $1(\mathrm{Y})$ and your counterpart chooses $1(\mathrm{Y})$,

Your points $=100 \times 1 \times 1+60 \times(1-1)+30 \times(1-1)=100$

Points for your counterpart $=100 \times 1 \times 1+60 \times(1-1)+100 \times(1-1)=100$

The point table in this example will be as follows.

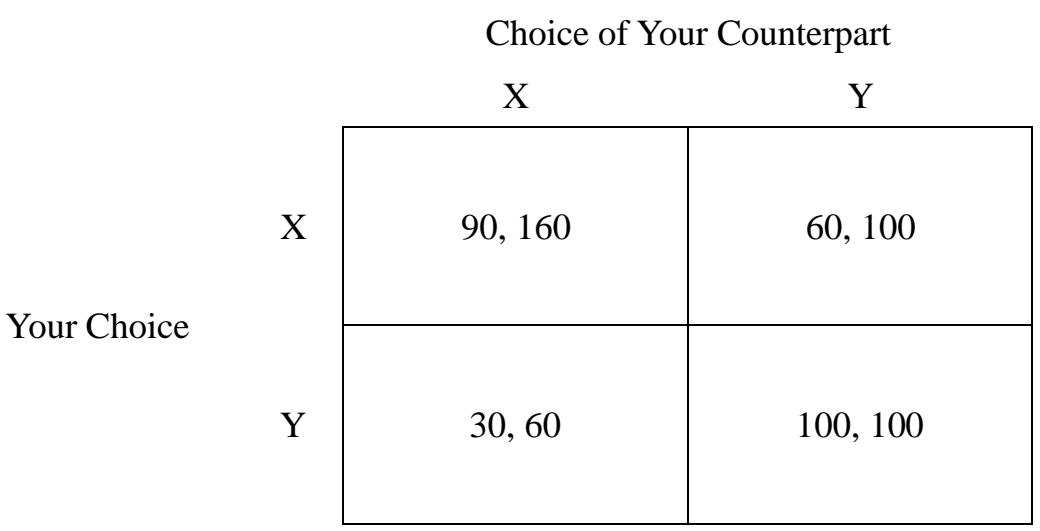


When the choice of your counterpart is $0(\mathrm{X})$ and your choice is changed from 0 to 1 , the points for you and your counterpart can be graphed as follows.

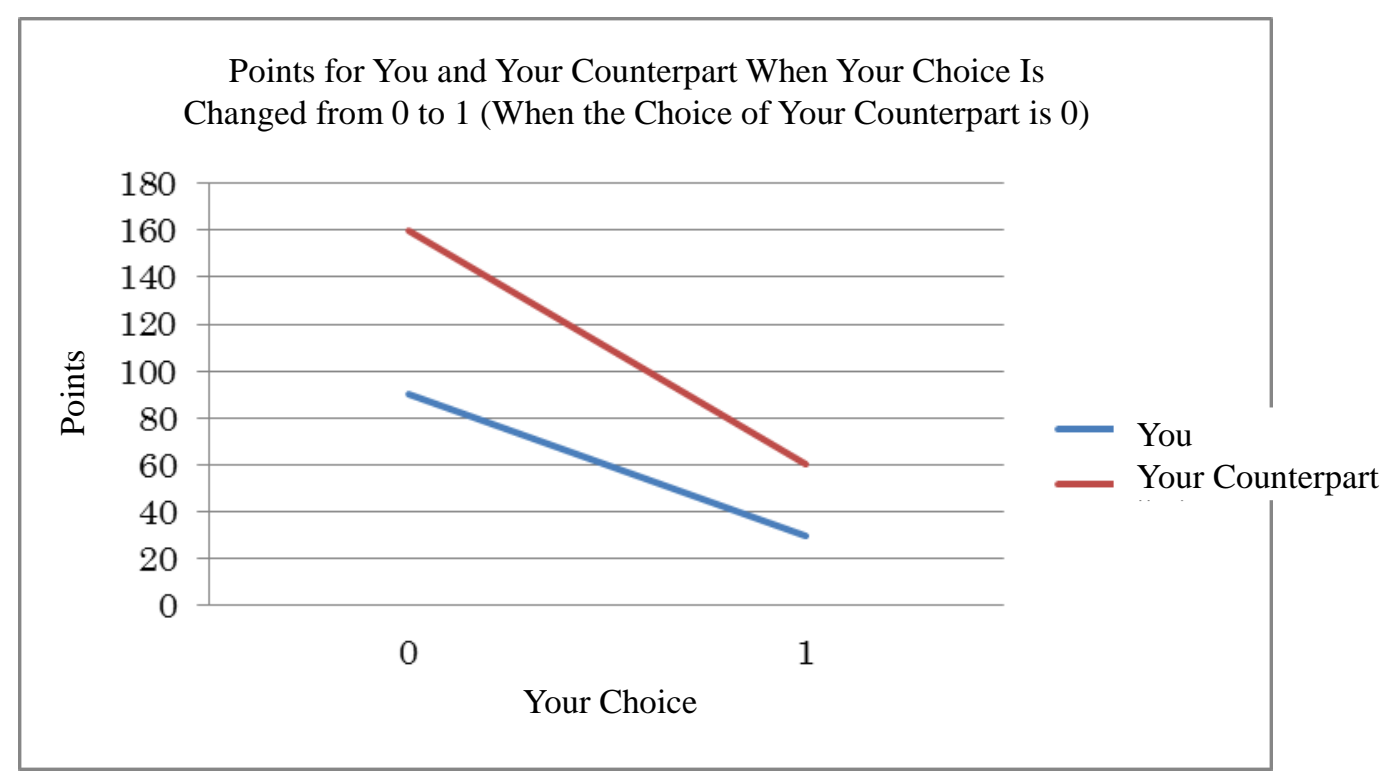

When the choice of your counterpart is $1(\mathrm{Y})$ and your choice is changed from $0(\mathrm{X})$ to $1(\mathrm{Y})$, the points for you and your counterpart can be graphed as follows.

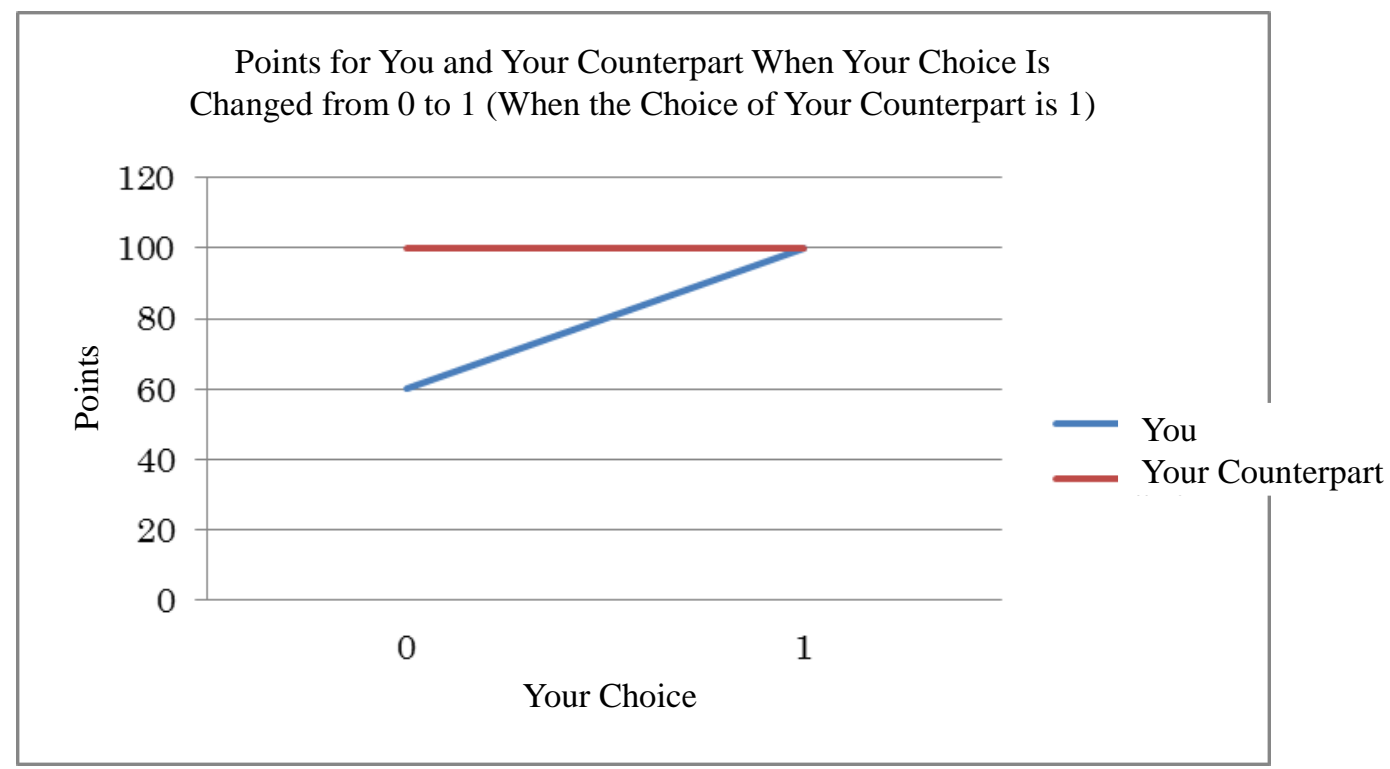




\section{Numerical Value Example 2}

Let us say the value of $s$ is 140 and the value of $t$ is 55 . In this case, the points will be as follows:

When you choose $0(\mathrm{X})$ and your counterpart chooses $0(\mathrm{X})$,

Your points $=100 \times 0 \times 0+60 \times(1-0)+140 \times(1-0)=200$

Points for your counterpart $=100 \times 0 \times 0+60 \times(1-0)+55 \times(1-0)=115$

When you choose $0(\mathrm{X})$ and your counterpart chooses $1(\mathrm{Y})$,

Your points $=100 \times 0 \times 1+60 \times(1-0)+140 \times(1-1)=60$

Points for your counterpart $=100 \times 0 \times 1+60 \times(1-1)+55 \times(1-0)=55$

When you choose $1(\mathrm{Y})$ and your counterpart chooses $0(\mathrm{X})$,

Your points $=100 \times 1 \times 0+60 \times(1-1)+140 \times(1-0)=140$

Points for your counterpart $=100 \times 1 \times 0+60 \times(1-0)+55 \times(1-1)=60$

When you choose $1(\mathrm{Y})$ and your counterpart chooses $1(\mathrm{Y})$,

Your points $=100 \times 1 \times 1+60 \times(1-1)+140 \times(1-1)=100$

Points for your counterpart $=100 \times 1 \times 1+60 \times(1-1)+55 \times(1-1)=100$

In other words, the point table in this example will be as follows.

\begin{tabular}{|c|c|c|}
\hline & Choice & terpart \\
\hline & $\mathrm{X}$ & $\mathrm{Y}$ \\
\hline $\mathrm{X}$ & 200, 115 & 60,55 \\
\hline Y & 140,60 & 100,100 \\
\hline
\end{tabular}


When the choice of your counterpart is $0(\mathrm{X})$ and your choice is changed from 0 to 1 , the points for you and your counterpart can be graphed as follows.

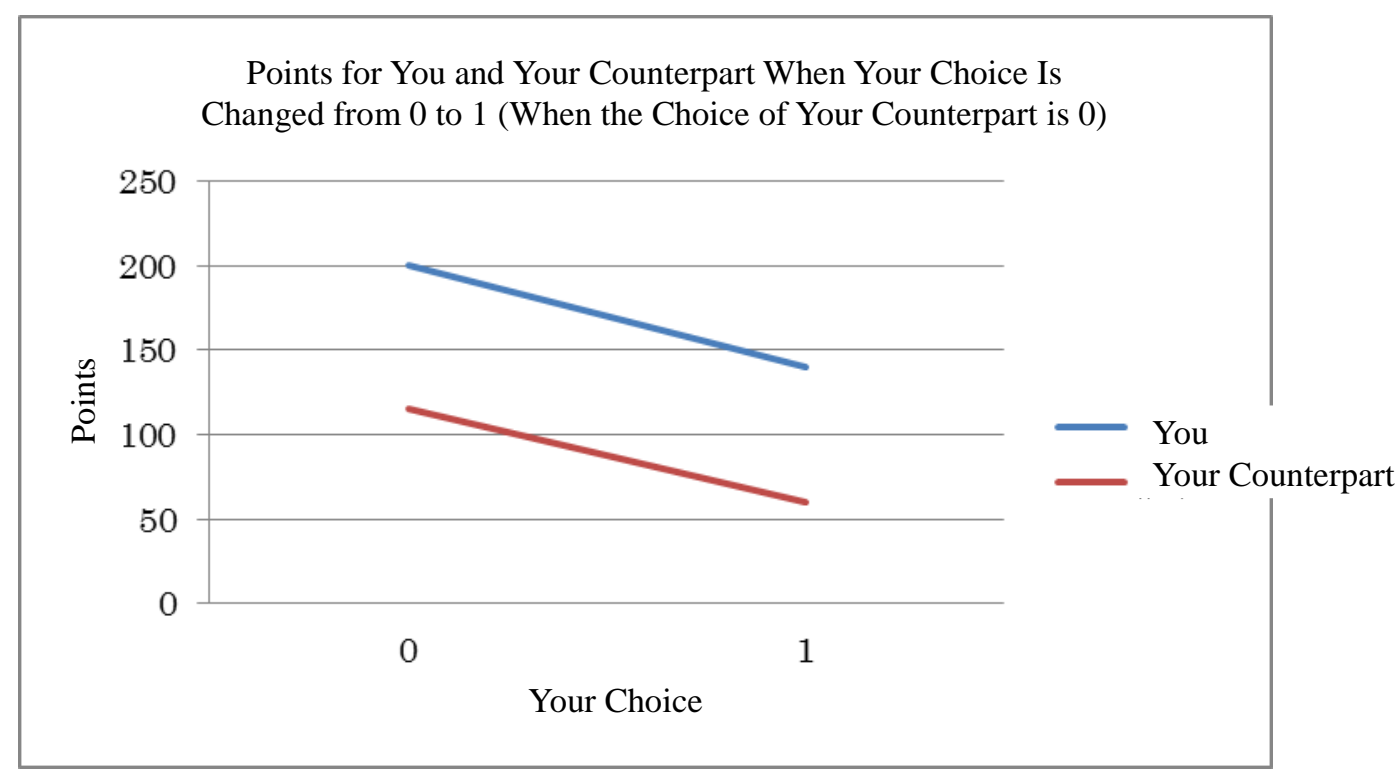

When the choice of your counterpart is $1(\mathrm{Y})$ and your choice is changed from $0(\mathrm{X})$ to $1(\mathrm{Y})$, the points for you and your counterpart can be graphed as follows.

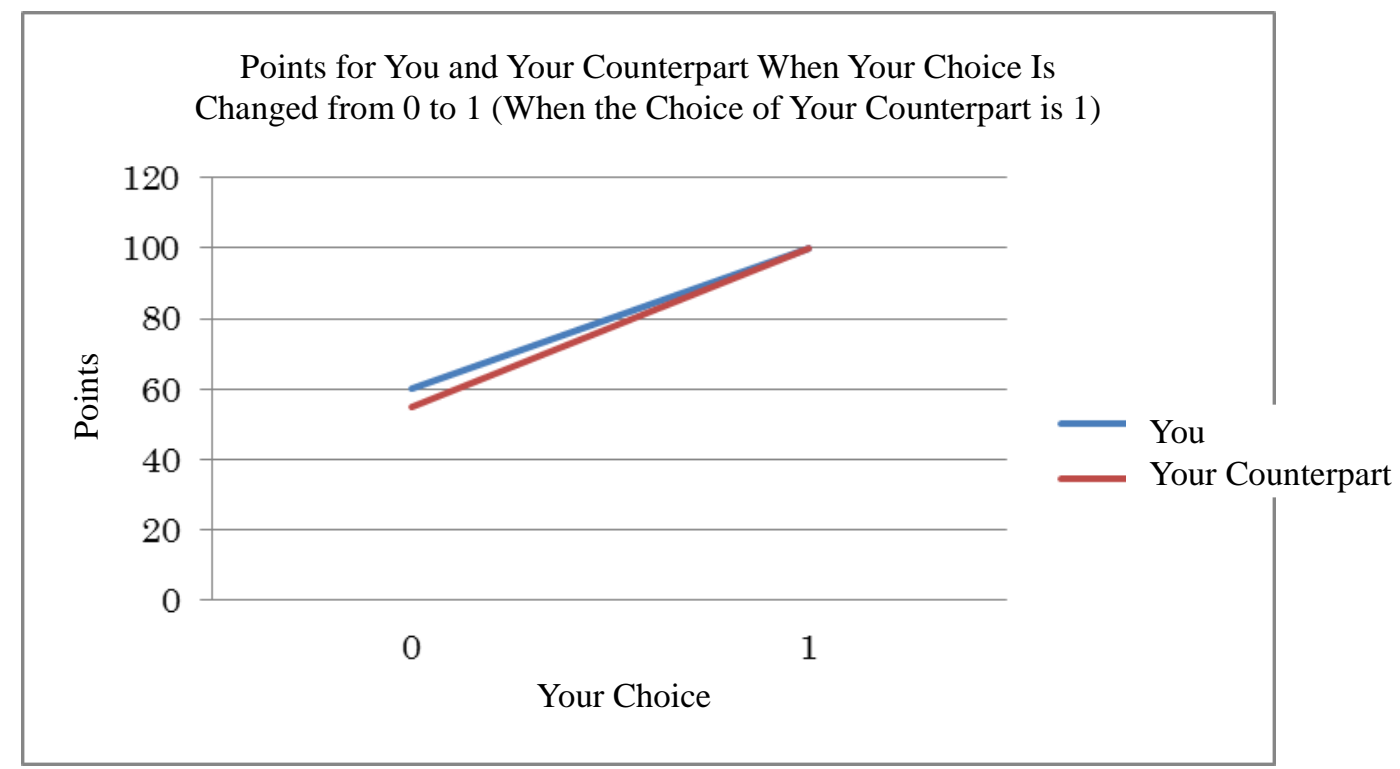


Explanation of the Computer Screen and the Tasks to Be Performed during the Experiment Selection screen

\section{Round}

$1 / 6$

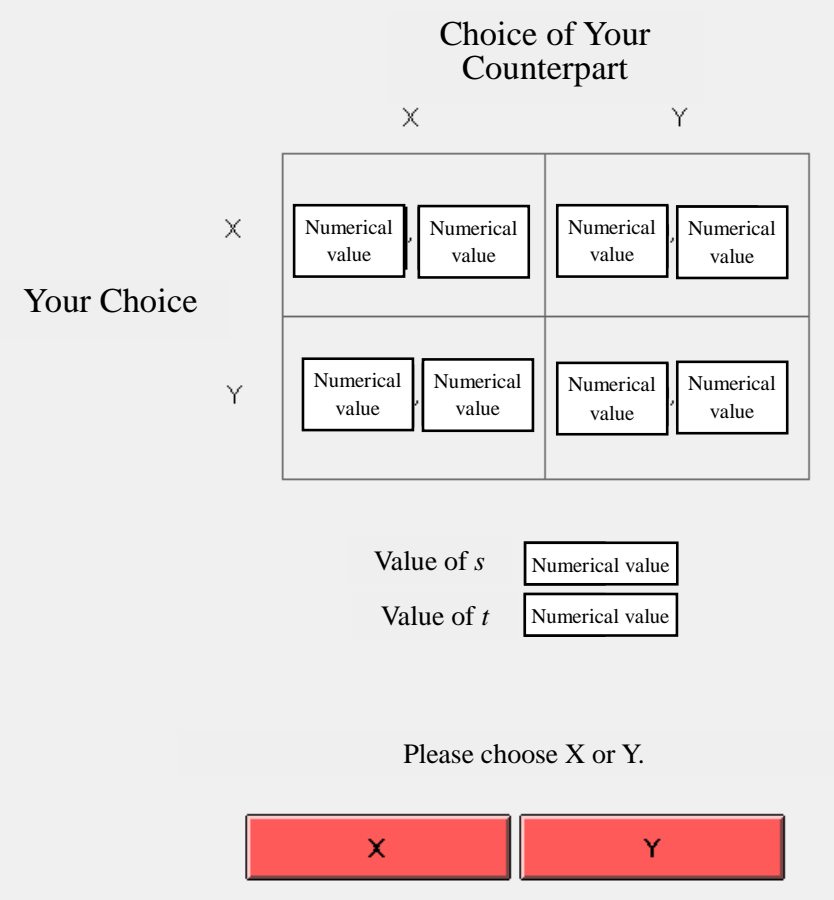

The selection screen will display the above. The point table is displayed in the center of the screen. Below it, you will find the values of $s$ and $t$ that are used in the formulae to derive the points. Below that are the selection buttons.

First, please choose X or Y and write it under "Your Choice" on the record sheet. Please also write why you made that choice in the "Reasons for Your Choice" section.

When you finish writing, please click on the button for the option you wrote in "Your Choice."

Once everyone clicks a selection button, the next round will begin. 
Results screen

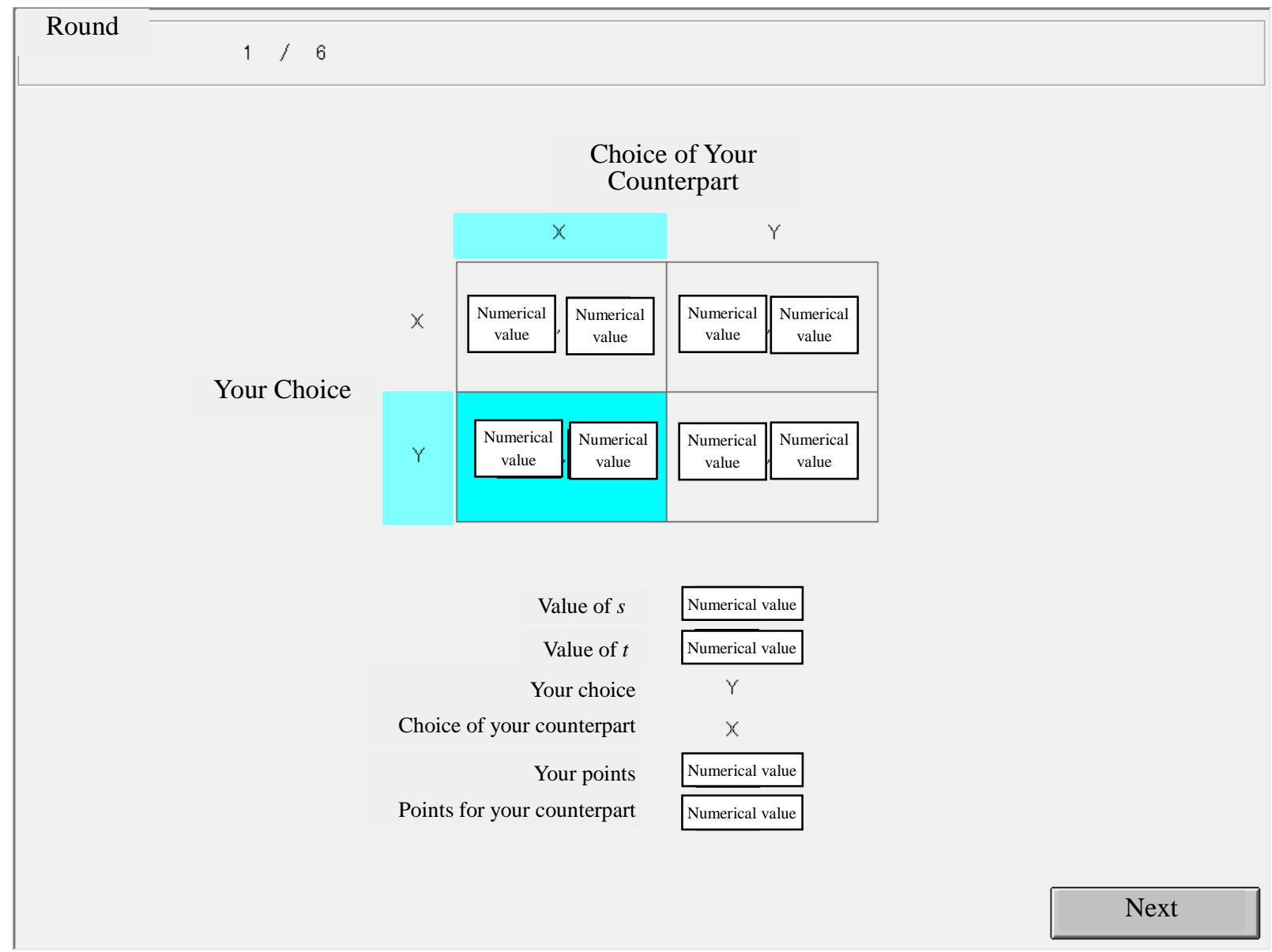

The results screen will display the above. The values of $s$ and $t$ that are used in the formulae to derive the points, your choice, the choice of your counterpart, your points, and the points for your counterpart are displayed below the center of the screen.

First, please write the choice of your counterpart displayed on the screen under "Choice of Your Counterpart" on the record sheet. Please also write your points displayed on the screen in the "Your Points" section.

When you finish writing, please click on the Next button at the lower right of the screen.

Once all subjects click the Next button, the next round will begin. This will complete the first round of selection. This process is repeated six times.

You will now have three minutes to review the details of the experiment. If you have a question, please raise your hand quietly and the experimenter will answer you one-to-one. Please note that you are not allowed to communicate with the other participants. 


\section{Part 3}

Explanation of the Experiment Details

You will make six rounds of selections as explained below. First, you will be paired with another participant. The individual you are paired with will be randomly chosen by the computer for each round of selection.

This part is composed of two stages.

\section{Stage 1}

You will choose one of two options, $\mathrm{X}$ and $\mathrm{Y}$. The points for you and your counterpart will be determined on the basis of the choices you and your counterpart make.

\begin{tabular}{|c|c|c|c|}
\hline & & Choice of Y & - Counterpart \\
\hline & & $X$ & $\mathrm{Y}$ \\
\hline & $X$ & $\begin{array}{l}\text { Numerical value } a \text {, } \\
\text { Numerical value } b\end{array}$ & $\begin{array}{l}\text { Numerical value } c \text {, } \\
\text { Numerical value } d\end{array}$ \\
\hline & $\mathrm{Y}$ & $\begin{array}{l}\text { Numerical value } e \text {, } \\
\text { Numerical value } f\end{array}$ & $\begin{array}{l}\text { Numerical value } g \text {, } \\
\text { Numerical value } h\end{array}$ \\
\hline
\end{tabular}

This point table is read the same way as the previous one. Points $a$ through $h$ will each have a specific numerical value during the experiment and will change in each round. The numerical values in the point table are derived by the method explained in Part 2.

\section{Stage 2}

After verifying each other's choice and points in Stage 1, you will have an opportunity to give some of your points to your counterpart.

For example, let us say that your choice was $\mathrm{X}$ and the choice of your counterpart was $\mathrm{Y}$ in Stage 1 and that you and your counterpart earned $c$ points and $d$ points, respectively. Furthermore, let us say that you and your counterpart decided to give 10 points and 15 points to each other, respectively, in Stage 2. In this case, your final points will be $c-10+15$, while the points for your counterpart will be $d-15+10$.

Note: please choose an integer of 0 or larger that is smaller than the number of points you earned in Stage 1 to give to your counterpart. 
Explanation of the Computer Screen and the Tasks to Be Performed during the Experiment Selection screen in Stage 1

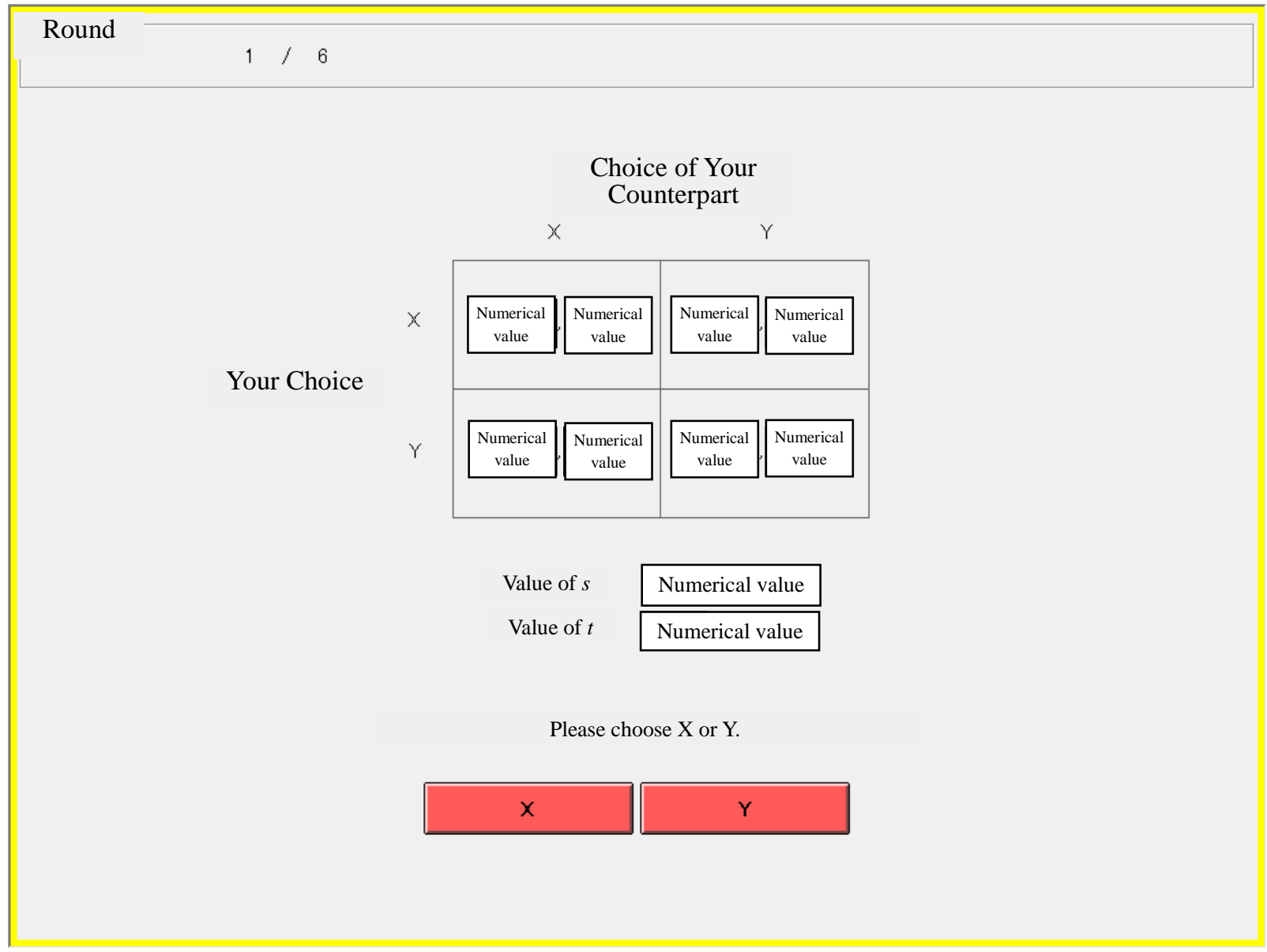

The selection screen in Stage 1 will display the above. The point table is displayed in the center of the screen. Below it, you will find the values of $s$ and $t$ that are used in the formulae to derive the points. Below that are the selection buttons.

First, please choose X or Y and write it under "Your Choice in Stage 1" on the record sheet. Please also write why you made that choice in the "Reasons for Your Choice in Stage 1" section.

When you finish writing, please click on the button for the option you wrote in "Your Choice in Stage 1."

Once all subjects click on a selection button, you will proceed to the selection screen in Stage 2. 
Selection screen in Stage 2

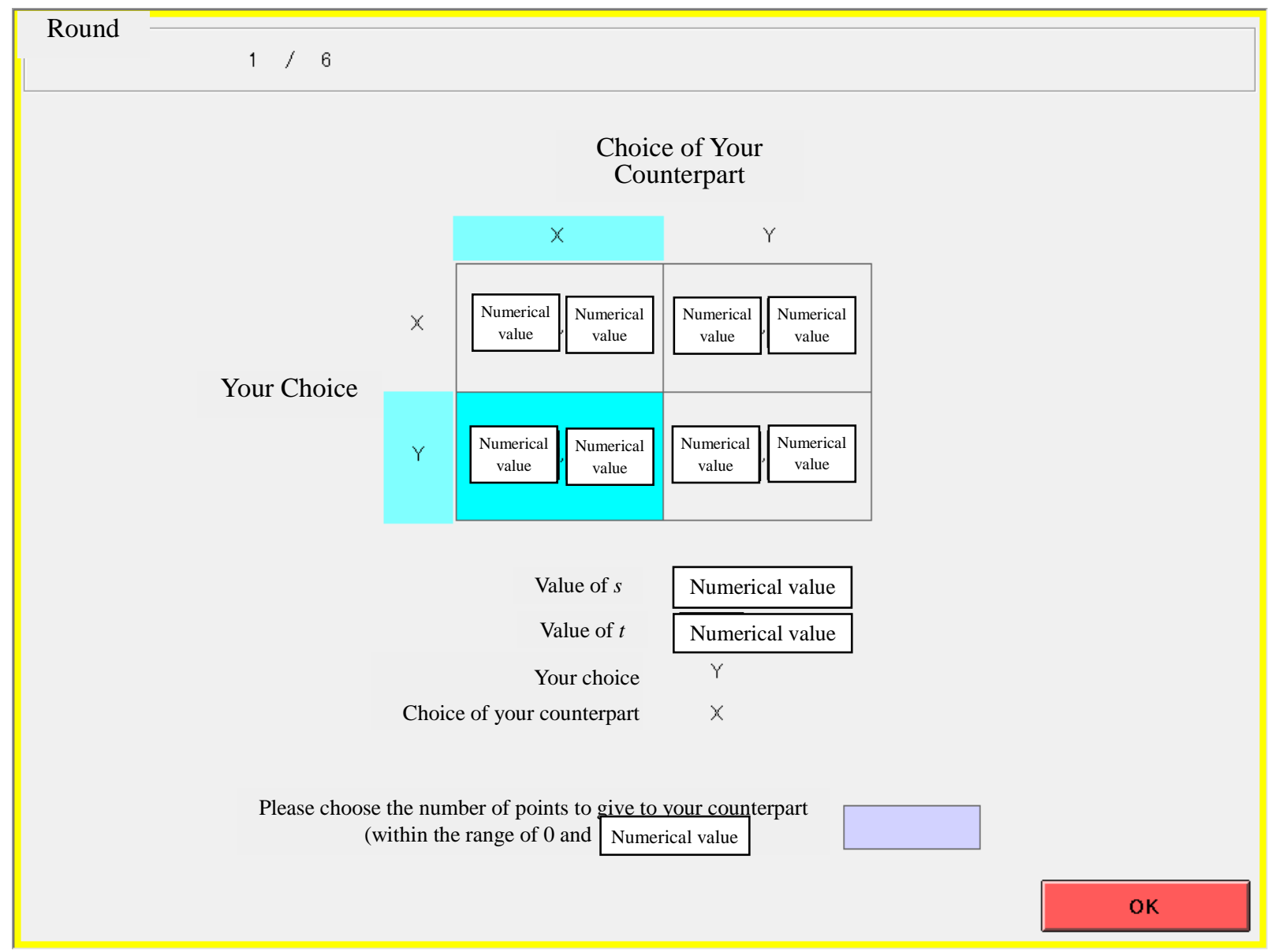

The selection screen in Stage 2 will display the above. The values of $s$ and $t$ that are used in the formulae to derive the points as well as your choice and the choice of your counterpart in Stage 1 are displayed in the center of the screen. Below that is the selection box.

First, please write the choice of your counterpart displayed on the screen under "Choice of Your Counterpart in Stage 1" on the record sheet.

Next, please write the number of points you are giving to your counterpart under "Your Choice in Stage 2" on the record sheet. For the number of points to give, please choose an integer that is 0 or larger that does not exceed the number of points you earned in Stage 1. Please also write why you made that choice in the "Reasons for Your Choice in Stage 2" section.

When you finish writing, please enter the numerical value you wrote in "Your Choice in Stage 2" and click the OK button on the lower right.

Once all subjects click on the OK button, you will proceed to the results screen. 


\section{Results screen}

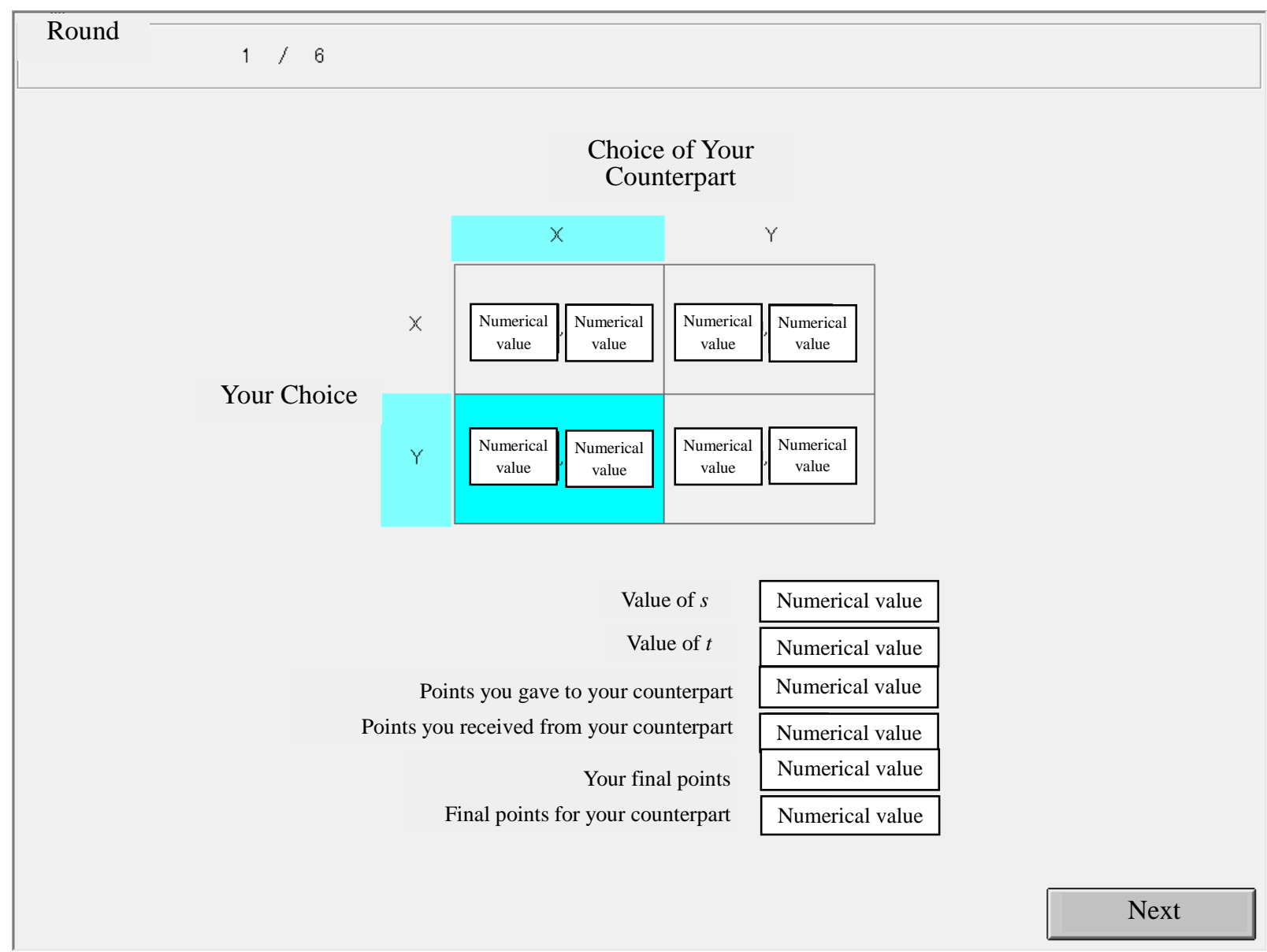

The results screen will display the above. The values of $s$ and $t$ that are used in the formulae to derive the points as well as points you gave to your counterpart, points you received from your counterpart, your final points, and the final points for your counterpart are displayed in the center of the screen.

First, please write the points you received from your counterpart as displayed on the screen under "Choice of Your Counterpart in Stage 2" on the record sheet. Please also write your final points displayed on the screen in the "Your Point" section in the record sheet.

When you finish writing, please click the Next button on the lower right of the screen.

Once all subjects click on the Next button, the next round will begin. This will complete the first round of selection. This process is repeated six times.

You will now have three minutes to review the details of the experiment. If you have a question, please raise your hand quietly and the experimenter will answer you one-to-one. Please note that you are not allowed to communicate with the other participants. 


\section{Part 4}

Explanation of the Experiment Details

You will make six rounds of selections as explained below. First, you will be paired with another participant. The individual you are paired with will be randomly chosen by the computer for each round of selection.

Part 4 is composed of three stages.

\section{Stage 1}

After verifying the point table for Stage 2 (explained later), you will choose whether to proceed to Stage 3 (choose Yes; explained later) or not (choose No).

If you or your counterpart (or both) choose Yes, you will proceed to Stage 3. When both of you choose No, you will not proceed to Stage 3, and the points you earned in Stage 2 will become your final points.

\section{Stage 2}

After verifying each other's choice in Stage 1 and determining whether to proceed to Stage 3, you will choose one of two options, $\mathrm{X}$ and $\mathrm{Y}$. The points for you and your counterpart will be determined on the basis of the choices you and your counterpart make.

\begin{tabular}{|c|c|c|c|}
\hline & & Choice of Y & - Counterpart \\
\hline & & $\mathrm{X}$ & $\mathrm{Y}$ \\
\hline & $\mathrm{X}$ & $\begin{array}{l}\text { Numerical value } a \text {, } \\
\text { Numerical value } b\end{array}$ & $\begin{array}{l}\text { Numerical value } c \text {, } \\
\text { Numerical value } d\end{array}$ \\
\hline & $\mathrm{Y}$ & $\begin{array}{l}\text { Numerical value } e \text {, } \\
\text { Numerical value } f\end{array}$ & $\begin{array}{l}\text { Numerical value } g \text {, } \\
\text { Numerical value } h\end{array}$ \\
\hline
\end{tabular}

This point table is read in the same way as the previous ones. Points $a$ through $h$ will have a specific numerical value during the experiment and will change in each round. The numerical values in the point table are derived by the method explained in Part 2.

\section{Stage 3}

After verifying each other's choice and points in Stage 2, you will have an opportunity to give some of the points you have to your counterpart.

Please choose an integer of 0 or larger that is smaller than the number of points you earned in Stage 2 as the number of points to give to your counterpart. 
Explanation of the Computer Screen and the Tasks to Be Performed during the Experiment Selection screen in Stage 1

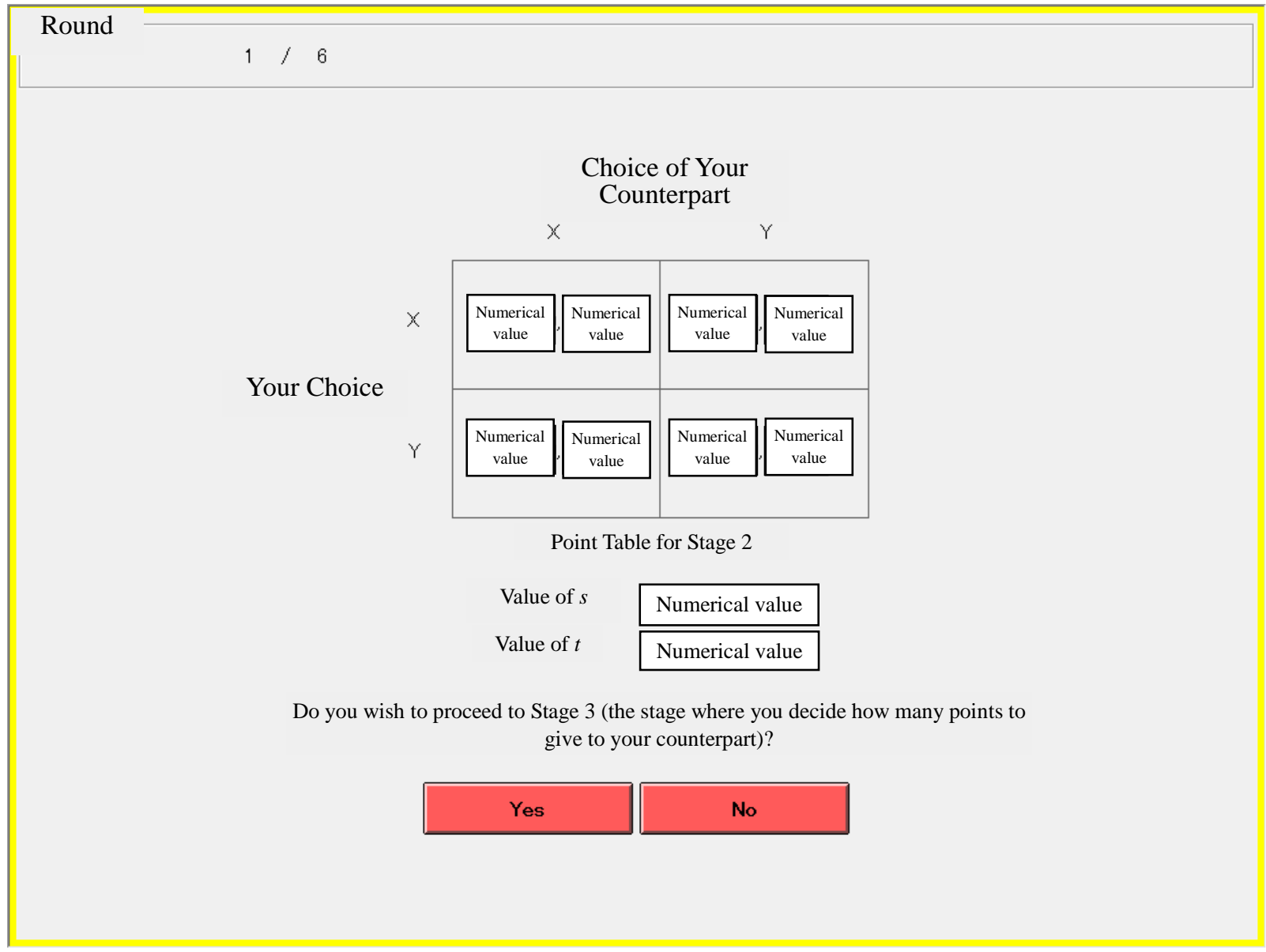

The selection screen in Stage 1 will display the above. The point table in Stage 2 is displayed in the center of the screen. Below it, you will find the values of $s$ and $t$ that are used in the formulae to derive the points. Below that are the selection buttons.

First, please choose Yes or No and write it under "Your Choice in Stage 1" on the record sheet. Please also write why you made that choice in the "Reasons for Your Choice in Stage 1" section.

When you finish writing, please click on the button for the option you wrote in "Your Choice in Stage 1."

Once everyone clicks a selection button, you will proceed to the selection screen in Stage 2. 
Selection screen in Stage 2

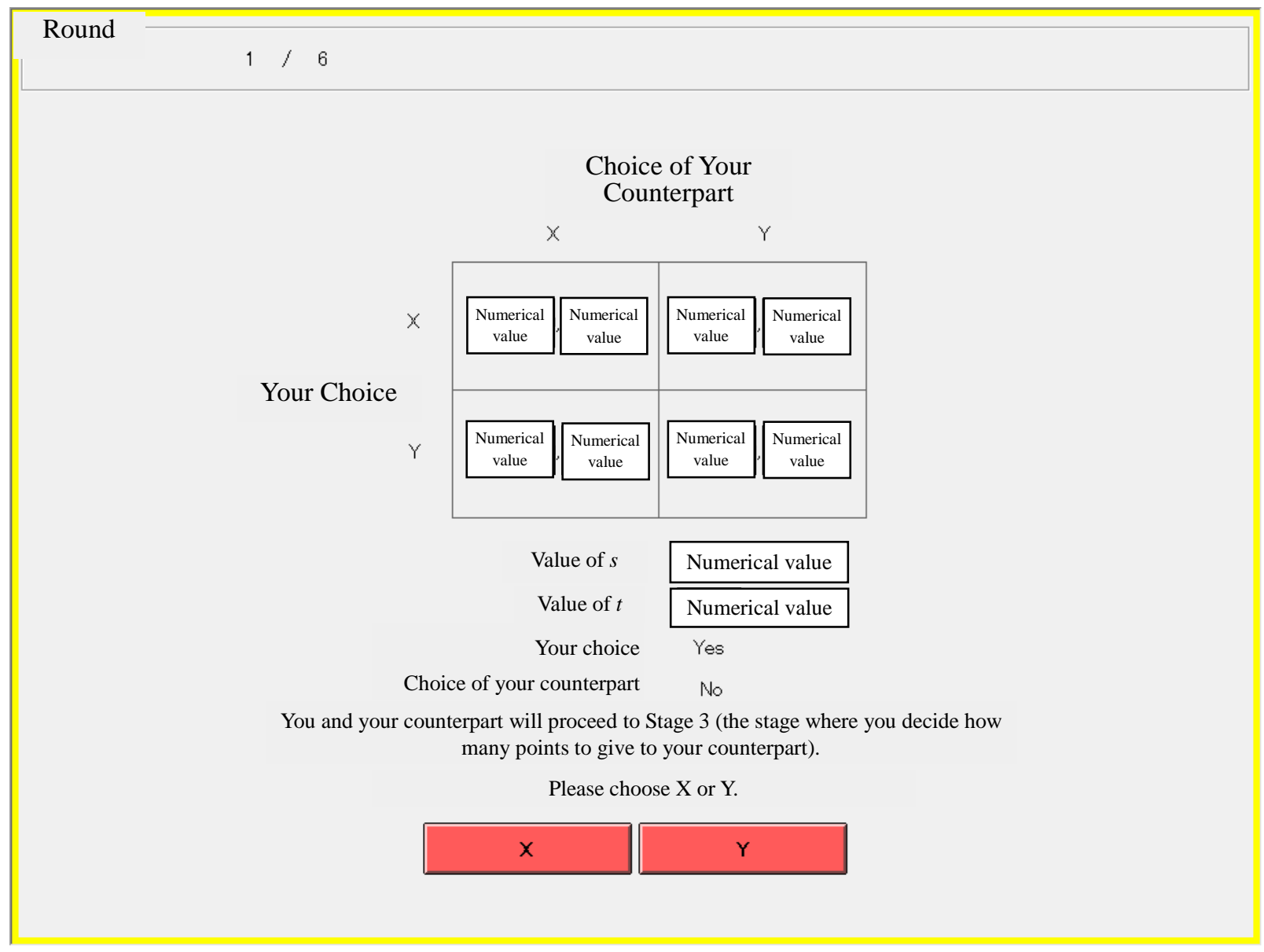

The selection screen in Stage 2 will display the above. The values of $s$ and $t$ that are used in the formulae to derive the points, your choice and the choice of your counterpart in Stage 1, and whether to proceed to Stage 3 (the stage where you decide how many points to give to your counterpart) are displayed in the lower center of the screen.

First, please write down the choice of your counterpart displayed on the screen under "Choice of Your Counterpart in Stage 1" on the record sheet.

Next, please choose X or Y and write it in the "Your Choice in Stage 2" section in the record sheet. Please also write why you made that choice in the "Reasons for Your Choice in Stage 2" section.

When you finish writing, please click on the button for the option you wrote in "Your Choice in Stage 2."

Once all subjects click on a selection button, the selection screen in Stage 3 will be displayed to the pairs who are proceeding to Stage 3. For those not proceeding to Stage 3, the screen will say, "Other participants are playing. Please wait for a while.” Please wait until the results screen is displayed. 
Selection screen in Stage 3

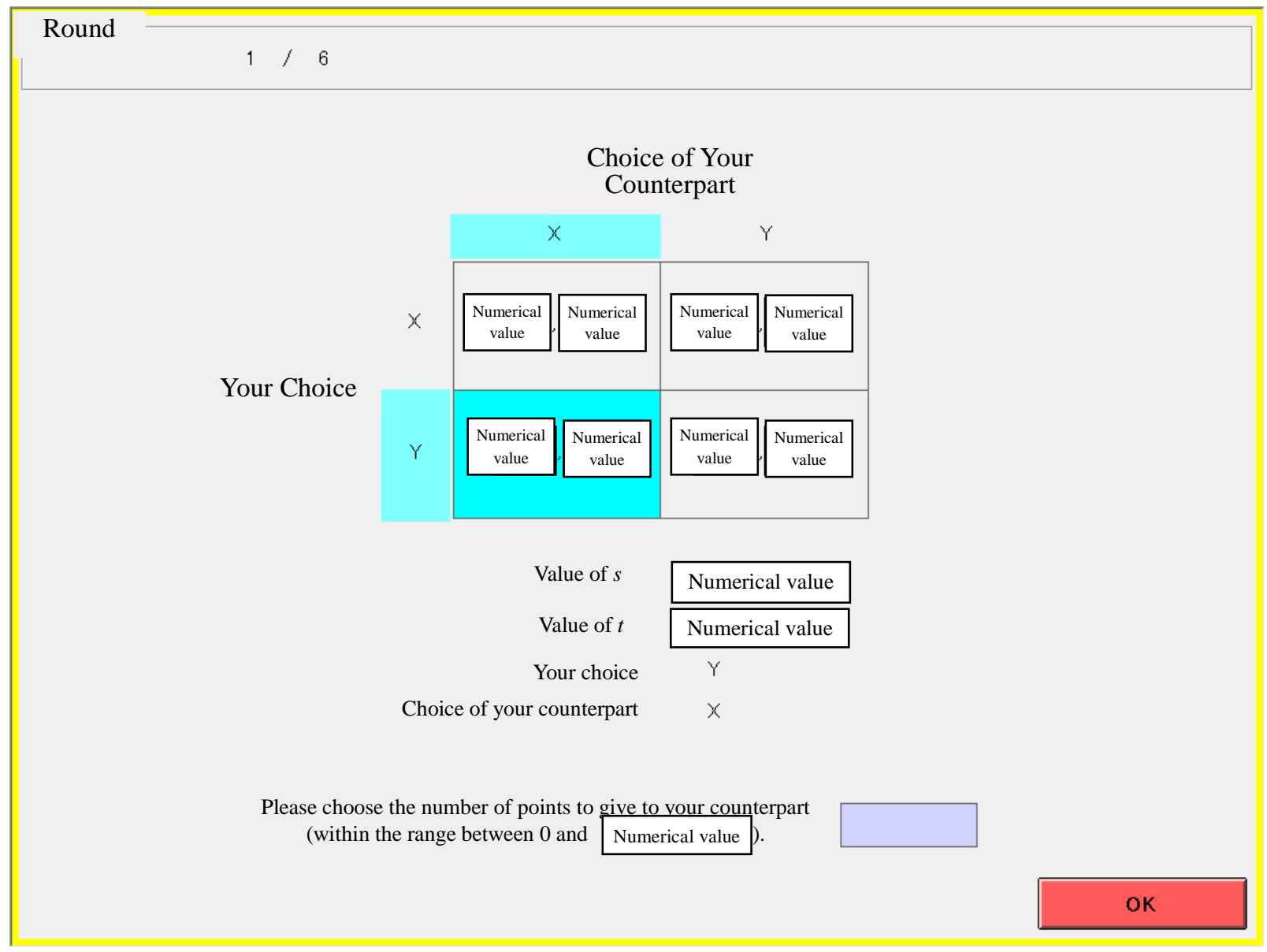

The above screen will be displayed for the pairs who proceeded to Stage 3. The values of $s$ and $t$ that are used in the formulae to derive the points as well as your choice and the choice of your counterpart in Stage 2 are displayed in the lower center of the screen. Below that is the selection box.

First, please write down the choice of your counterpart displayed on the screen under "Choice of Your Counterpart in Stage 2" in the record sheet.

Next, please write down the number of points you are giving to your counterpart in the "Your Choice in Stage 3" section in the record sheet. To give points, please choose an integer that is 0 or larger that does not exceed the number of points you earned in Stage 2. Please also write why you made that choice in "Reasons for Your Choice in Stage 3.”

When you finish write, please enter the numerical value you wrote in the "Your Choice in Stage 3" section and click the OK button on the lower right.

Once all the subjects who proceeded to Stage 3 click on the OK button, you will proceed to the results screen. 
Results screen for those proceeding to Stage 3

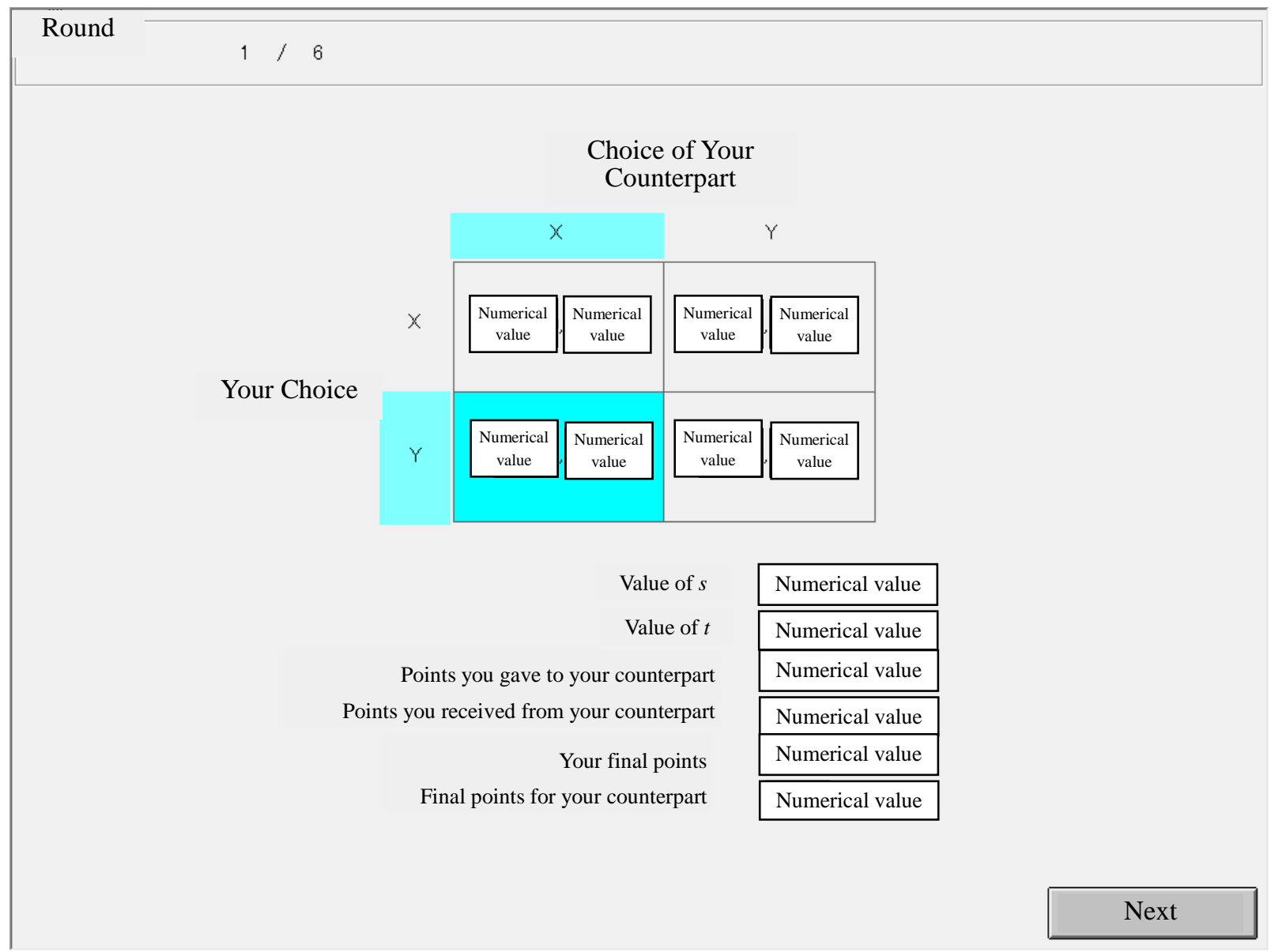

When you proceed to Stage 3, the results screen will display the above. The values of $s$ and $t$ that are used in the formulae to derive the points, the points you gave to your counterpart, the points you received from your counterpart, your final points, and the final points for your counterpart are displayed in the lower center of the screen.

First, please write down the choice of your counterpart displayed on the screen under "Choice of Your Counterpart in Stage 3" in the record sheet. Please also write down your final points displayed on the screen in the "Your Points" section.

When you finish writing, please click the Next button on the lower right of the screen.

Once all subjects click on the Next button, the next round will begin. 
Results screen for those not proceeding to Stage 3

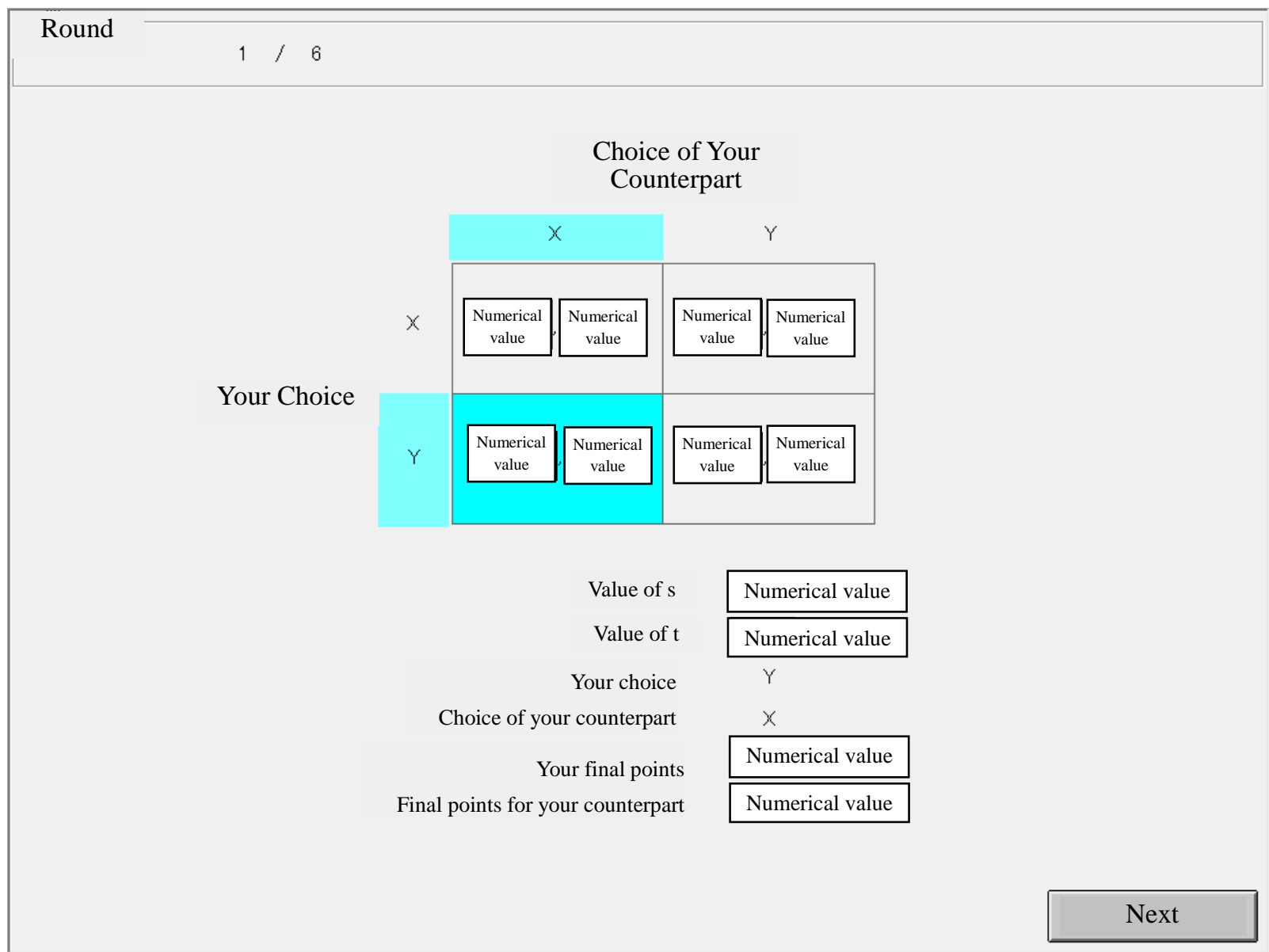

If you did not proceed to Stage 3, the results screen will display the above. The values of $s$ and $t$ that are used in the formulae to derive the points, your choice and the choice of your counterpart in Stage 2, your final points, and the final points for your counterpart are displayed in the lower center of the screen.

First, please write down the choice of your counterpart displayed on the screen under "Choice of Your Counterpart in Stage 2" in the record sheet. Please also write down your final points displayed on the screen in the "Your Points" section. You do not need to fill out "Your Choice in Stage 3," "Reason for Making the Choice You Made in Stage 3,” or "The Choice of Your Counterpart in Stage 3.”

When you finish writing, please click the Next button on the lower right of the screen.

Once all subjects click on the Next button, the next round will begin. This completes one selection. This process is repeated six times.

You will now have three minutes to review the details of the experiment. If you have a question, please raise your hand quietly and the experimenter will answer you one-to-one. Please note that you are not allowed to communicate with the other subjects. 